\title{
A Six-Sigma DMAIC Approach to Improve the Sales Process of a Technology Start-Up
}

\author{
Desy Wartati \\ Warwick Manufacturing Group, \\ University of Warwick, Coventry, CV4 7AL, United Kingdom. \\ E-mail: desywartati@gmail.com \\ Jose Arturo Garza-Reyes \\ Centre for Supply Chain Improvement, \\ University of Derby, Kedleston Road Campus, Derby, DE22 1GB, United Kingdom. \\ Corresponding author: J.Reyes@derby.ac.uk \\ Marcos Dieste \\ Faculty of Science and Technology, \\ Free University of Bozen-Bolzano, Universitätsplatz 5, 39100, Bolzano, Italy. \\ E-mail: marcos.dieste@unibz.it \\ Simon Peter Nadeem \\ Centre for Supply Chain Improvement, \\ University of Derby, Kedleston Road Campus, Derby, DE22 1GB, United Kingdom. \\ E-mail: S.Nadeem@derby.ac.uk \\ Rohit Joshi \\ Indian Institute of Management Shillong, Shillong, India. \\ E-mail: rj@iimshillong.ac.in \\ Fernando González-Aleu \\ Departamento de Computación e Ingeniería Industrial, \\ Universidad de Monterrey, San Pedro Garza García, N.L., Mexico. \\ E-mail: fernando.gonzalezaleu@udem.edu
}

(Received on June 8, 2021; Accepted on October 12, 2021)

\begin{abstract}
Despite the adoption of Six-Sigma in different service sectors, its application in the Sales function of a Technology-based Start-up has not been explored. This paper deploys an action research-based study methodology and conducts a thorough analysis of a Technology Start-up company in Indonesia, using Six-Sigma principles and the Define-Measure-AnalyseImprove-Control (DMAIC) approach. Statistical validation of the causes of problems helped to formulate a strategy that may have otherwise not been possible. The results of the study and proposed solutions confirm the potential benefits of adopting Six-Sigma in the Sales function of technology start-ups to reduce, particularly, customer waiting time. The novelty of this research lies in the fact that it applies Six-Sigma in a transactional process such as sales, which earlier studies have not explored in depth. This paper can be employed as a reference for organisations to undertake and guide specific process improvement projects similar to the one presented.
\end{abstract}

Keywords- Six-Sigma, DMAIC, Transactional process, Sales process, Technology start-up. 


\section{Introduction}

Recent technological revolutions have led to the growth of technology-based start-up companies around the world. These ventures in the early stage of development are changing the traditional concept of doing business based on technology-driven approaches (Skala, 2019; Lameijer et al., 2021). Apart from the technology's role in start-up companies, sales and distribution strategies are still a major part of this sector, thus it is crucial to establish an appropriate sales execution strategy to help these firms bring products or services to market efficiently and effectively (Feinleib, 2011; Gilbert and Davies, 2011). However, developing a viable sales strategy turns out to be a challenge for many start-ups (Skala, 2019). Some start-ups focus aggressively on their sales strategy before they have figured out how to make products or services profitable (Feinleib, 2011) while others overlook the importance of the sales strategy (Gilbert and Davies, 2011). For the latter case, it substantially affects the continuity of sales execution processes, including customer service speed and customer waiting time, which is closely linked to customer satisfaction (Cohan, 2019).

During the last decades, different quality management concepts, including Total Quality Management (TQM), Six-Sigma and lean thinking, have been applied in many different contexts to resolve quality problems (Yadav et al., 2020; Dieste et al., 2021). In particular, the Six-Sigma methodology can be applied in a wide range of areas, including both manufacturing and service industries (Antony, 2004a; Chiarini, 2013). It was developed to help companies deal with issues such as waiting time and improve customer value. Six-Sigma focuses on defects prevention through the identification and elimination of errors in business processes by using statistical modelling and empirical methods (Chen and Lyu, 2009; Pyzdek and Keller, 2014). Moreover, it also targets to reduce cycle time and operating expense, improve productivity, and better respond to customer expectations (Karout and Awasthi, 2017).

Since its creation in Motorola in the 1980s (Antony, 2006), Six-Sigma has been widely adopted in the manufacturing sector (Srinivasan et al., 2016; Ben Ruben et al., 2017) and its application has been successful to reduce waiting time (Muralidharan, 2015) and increase customer satisfaction (Patel, 2017). Recently, the scope of Six-Sigma has expanded/evolved to the service sector and business functions such as sales and marketing (Antony, 2004b; Madhani, 2017; Lameijer et al., 2021). Thus, the suitability of the Six-Sigma application to improve sales activities in general and reducing/eliminating the causes of waiting time in sales processes is relevant as it provides a systematic solution for such quality problems. According to Antony et al. (2020) research in Six Sigma in SMEs and start-up enterprises should also be expanded as its implementation remains very challenging for the firm, but would be rewarding if implemented properly.

In this scope and by following an action research-based approach, this paper aims to achieve the following research objectives:

- Analyse the current state of the literature regarding the application of Six-Sigma in sales processes and Start-up companies.

- Deploy Six-Sigma principles and tools to improve the sales process of a Technology Start-up company.

- Utilise the DMAIC improvement cycle as the core problem-solving approach to improve the sales process of a Technology Start-up.

To achieve these objectives this research first reviews previous studies about Six-Sigma's application in the marketing and sales functions. Then, an action research-based study is deployed 
within a Technology Start-up based in Indonesia that aimed to improve its business performance, earn a considerable market valuation, and compete on an international level through efficient sales activities and minimising customer waiting time to enhance customer satisfaction. These issues were identified as critical by the company analysed.

This research and its contribution are novel as to the best of the authors' knowledge no in-depth study has been previously conducted regarding the application of Six-Sigma in the sales process of Technology related Start-ups. Thus, this research fills this gap by using Six-Sigma for business improvement in technology start-up companies by expanding the spectrum of Six-Sigma implementation in the service sector, specifically in the Sales function of Technology-based Startup companies. The analysis confirms that Six-Sigma techniques can be effectively utilised to solve problems in the Sales function. Additionally, this study can trigger interest among other technology start-ups to adopt statistical modelling methods such as Six-Sigma for business improvement.

\section{Literature Review}

Six-Sigma is described as a data-driven approach to improve business processes (Alblooshi et al., 2020) by reducing variability (Patel, 2017). Cudney and Agustiady (2017) state that the sigma level refers to the process capability of a company that "represents the number of standard deviations between the centre of a process and the closest specification limit". In other words, it is principally a strategy that aims to reduce defects and errors in all processes that are critical to the customer (Garza-Reyes et al., 2016).

Many companies have utilised Six-Sigma to drive improvements and strive for excellence in quality standards and customer satisfaction (Alkunsol et al., 2019), specifically in manufacturing sectors for reducing defects (Ben Ruben et al., 2017). Its adoption has now evolved further in service sectors (Shamsuzzaman et al., 2018) and the medical industry (Sunder et al., 2020). Although the concept of Six-Sigma was developed/adopted, initially, in the manufacturing sector, it is essentially a process improvement approach that can be used in diverse business areas (Jirasukprasert et al., 2014). These could include improving on-time delivery (Mishra and Rane, 2019), reducing cycle time for hiring and training new employees (Mehrjerdi, 2013), reducing the complaint resolution time across information technology organisations (Gijo et al., 2019), improving the average order fulfilment lead time for sales orders (Shamsuzzaman et al., 2018), or improving software quality (Karout and Awasthi, 2017).

The most important concept of Six-Sigma is a structured problem-solving approach that contains a five-phase improvement cycle, i.e. Define, Measure, Analyse, Improve, and Control (Garza-Reyes et al., 2016; Madhani, 2017). Utilising DMAIC to systematically approach/tackle problems helps to identify/resolve the root causes (Karout and Awasthi, 2017; Garza-Reyes et al., 2018) through a set of tools and techniques in each stage (Shamsuzzaman et al., 2018).

Historically, Six-Sigma has been prevalent in the manufacturing sector (Antony, 2006) and recently its adoption in the service sector has been also observed (Lameijer et al., 2021). However, its application in sales processes has not received much attention (Salzarulo et al., 2012; Antony et al., 2016; Sangabriel-Guillen et al., 2017) since there are limiting factors that can reduce its spread (e.g. difficulty in gathering and measuring data) (Chakrabarty and Tan, 2007). This paper addresses this gap in the scholarly literature. Many scholars question the ability of Six-Sigma to enhance sales and/or marketing processes. Pestorius (2007) and Madhani (2017) argue that there is a huge potential in applications of Six-Sigma, although transactional processes such as sales are considered 
to be one of the most challenging areas for Six-Sigma implementation. They argue that this challenge exists due to the difficulty to identify appropriate projects as there are fewer process variables that can be controlled. Salzarulo et al. (2012) contend that Six-Sigma's application in the marketing activities of a basketball sport event boosted the attendance number. Moreover, Oliya et al. (2012) found that Six-Sigma could assist in the improvement of a bank's sales and marketing process. Likewise, the adoption of Six-Sigma to increase operating and financial performance, in Swink and Jacobs' (2012) study, was incidentally associated with the improvement in sales growth.

Furthermore, the study conducted by Lee (2014) also confirms the usefulness of Six-Sigma to improve marketing and control the sales of a service company. Similarly, Antony et al. (2016) demonstrated that Six Sigma's application in Indian companies brought progressive improvements in sales, marketing, finance and other transaction-related processes. Sangabriel-Guillen et al. (2017) exhibited Six-Sigma projects as a value driver for sales and marketing in the soft drinks bottling industry. Scholarly research with empirical evidence suggests the potential of Six-Sigma utilisation in sales and/or marketing.

Technological advancement is immersed in almost all types of businesses and has transformed every aspect, including the way companies operate and carry out business activities (Nadeem et al., 2019). Such growth in technology and its adoption at a wide scale has led to the emergence/development of new start-ups, specifically operating in the technology sector. Such companies perform an important part in driving innovation (Hathaway, 2013). Nevertheless, like any other type of firm, Technology-based Startups also face several challenges as they also have limited resources, especially limited funds and budgets (Skala, 2019). Constrained with the limitations, start-ups must remain creative and innovative to both develop their specific product/services (Gilbert and Davies, 2011) and a strategy to enter the market with a unique and distinct approach. Due to the product/service being the major deliverables of the business, the focus remains on ensuring creativity and innovation in that and thus preventing them from considering the importance of how to deliver the products or services to market more efficiently and effectively. In other words, the majority of start-ups fail to reflect on their sales execution strategy to deliver value for customers as they focus more on being creative/innovative in their products/services. This is one of the many aspects where Six-Sigma principles and tools can be useful for start-up companies to improve their sales and marketing functions (Madhani, 2017; Lameijer et al., 2021). The correct adoption and implementation of Six-Sigma could enhance quality standards and customer satisfaction through the sales function of start-ups, as they need economical solutions for the achievement of superior quality to the customer (Patel, 2017). However, implementing SixSigma is still a huge challenge for start-ups and SMEs, but the benefits can be many. Antony et al. (2020) identify this emerging trend as a novel path for further research.

To sum up, previous studies largely overlooked (a) the implementation of Six-Sigma principles and tools to improve sales processes; and (b) the deployment of the DMAIC approach in a Technology Start-up context. These are research gaps that have not been extensively addressed in the Six-Sigma academic literature.

\section{Methodology}

Multiple Six-Sigma tools were utilised in the present research under the five phases of the DMAIC approach to investigate errors/mistakes in the process and to offer potential solutions to reduce waiting time within the context of a technology Start-up organisation, see Section 4. Similar to the works conducted by Krueger et al. (2014), Zhang et al. (2015), Garza-Reyes et al. (2016), 
Swarnakar and Vinodh (2016), and Noori and Latifi (2018), this study followed the traditional DMAIC structure (see Figure 1).

Once the DMAIC framework was designed, the Six-Sigma methodology was applied in the firm under analysis. This led to empirical research for which the most appropriate research methodologies are case study or action research (Shadish et al., 2002). Recently, the use of a single case study has been well accepted as a valid research approach (Garza-Reyes et al., 2016). However, the action research approach is considered as a more valid research method, especially when conducting continuous improvement projects (Dey et al., 2015; Gutierrez et al., 2015; GarzaReyes et al., 2016).

This study required the researchers to closely manage and track the deployment of the proposed Six-Sigma and DMAIC methods and the improvement project. Action research is the appropriate research method for investigating and generating practical solutions with the participation of representatives from the case companies in the research process (Prashar, 2020). The participation of the researchers was essential to lead and support such implementation and management (Gutierrez et al., 2015). Thus, action research was considered the most suitable methodology to carry out this study. The action research approach also guaranteed that the application challenges of the Six-Sigma framework were overcome with direct help from the researchers (Gutierrez et al., 2015). For this study, the action research approach proved to be a valuable method to test the SixSigma implementation and draw conclusions regarding its effectiveness (Garza-Reyes et al., 2016), while analysing the root causes of the waiting time in the onboarding stage (i.e. set-up the merchants on the company's platform) in the studied sales process.

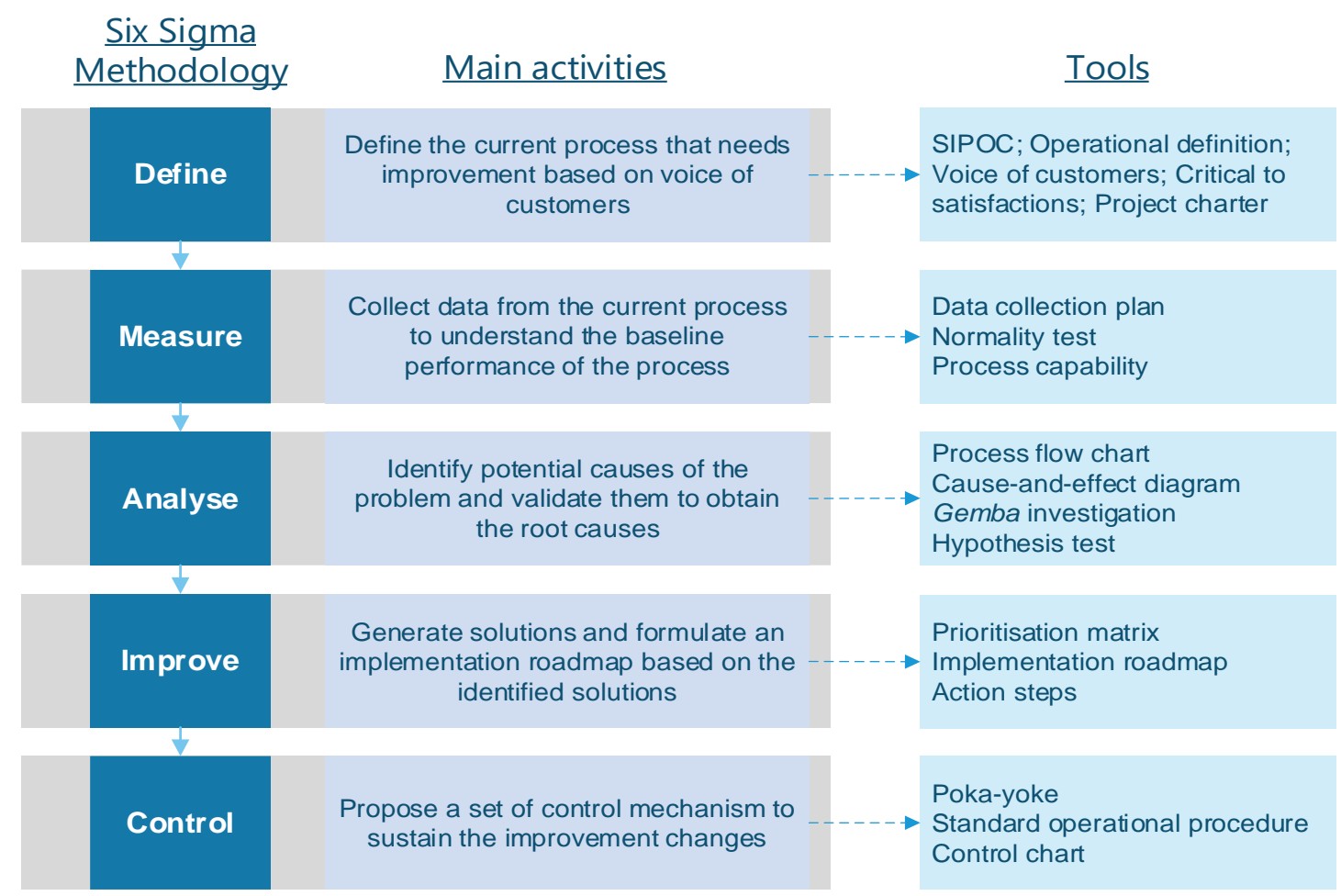

Figure 1. DMAIC framework and Six-Sigma tools. 
As part of the action research approach, the DMAIC methodology was employed simultaneously with several Six-Sigma tools as illustrated in Figure 1. This practical approach provides a structured method to solve a problem and achieve business improvement (Madhani, 2017). Furthermore, this methodology is also essential to analyse variation in waiting time (Gijo et al., 2014), which is in line with the concern of this study.

\section{Overview of the Organisation's Background}

The company selected for the study is a Technology Start-up (hereafter referred to as XYZ Company) with its headquarters based in Indonesia. The XYZ Company was established in 2010, offering on-demand transport for customers. In 2015, the company extended its business services by introducing a mobile application platform. With continuous growth and expansion, presently the company operates in over 50 cities across South-East Asia. It provides its services through a digital application, offering more than ten products of on-demand services, including motorcycle taxis, food delivery services, digital payments, shopping, delivering items, and other additional services. Among all the services, ordering and delivering food has become the most popular. The main clients of this product are restaurants that want to become a merchant and offer food delivery services using the platform of the XYZ Company. This merchant is called "partner" and once registered on the mobile application of XYZ Company, they can be easily found by millions of customers. Afterwards, customers order foods from registered restaurants using the company's apps.

The scope of this research concentrated on analysing the food delivery service within the regional partners based in a certain region of Indonesia. This referred to the requirement of the company itself and also the reports of the problems that their merchants were facing in waiting time within the onboarding stage (one part of the sales process), which delayed the overall sales activities.

\subsection{The Sales Process}

One of the most critical steps towards a profitable and sustainable food delivery business is acquiring more partners, which can be achieved by increasing sales activity (Upadhyay et al., 2019). In this regard, a sales team plays a vital role as they are responsible for bringing in new clients and maintaining good relationships with them. To increase sales activity, a significant step is to ensure the efficiency of the sales process so the company can shorten the sales cycle and accelerate time to revenue (Hase and Busch, 2018).

Company XYZ had the following three major stages in the sales process:

- Prospecting: this initial step involves the identification of potential buyers (merchants), then shortlisting the list to convert them from potential customers to current customers. This step includes developing a database of merchants and communicating with them to build rapport.

- Onboarding: afterwards, the sales team continue to work with the merchants to get them set up on the company's platform. The merchants fill in a form sent to their email, or they register directly in the office. Thereafter, the contract documents are signed with the merchant. Then, all the information is forwarded to the sales support team for final checks and content division as a requirement for the platform setting. The sales team perform the merchants' onboarding manually and manage their data via spreadsheets in Microsoft Excel and Google Sheets.

- Following-up: as a final step, the merchants will be informed about the account activation. The sales team still stay in contact with the merchants and provides after-sales support. 


\subsection{The Problem Faced by XYZ Company}

The company's records and historical data indicated that the firm was struggling with waiting time problems in the onboarding stage of the sales process. In this case, the new merchant application ranged from 30-50 applications/day. However, since the sales team also performed the onboarding manually, the waiting time for getting the contract process completed was higher than normal. This problem was critical not only for sales efficiency but also for other divisions in the firm, such as the sales support and content division, which needed inputs from the onboarding stage to design and set up the platform so the merchant could start their business with Company XYZ. Therefore, the onboarding stage was selected for Six-Sigma application.

\section{DMAIC Cycle Application}

As discussed in Section 4.2, the merchant's waiting time at this stage had been a critical issue for sales efficiency. According to the firm, this was one of the main causes of the decrease in customer satisfaction. In this section, a Six-Sigma problem-solving methodology, DMAIC is deployed to identify and reduce/eliminate the causes that contributed to increased waiting time for the merchant. This section presents the five phases of the DMAIC methodology adopted for this research (see Figure 1), elucidating a detailed analysis under each phase.

\subsection{The Define Phase}

In this phase, the first step was to form the project team that would carry out all the steps under the DMAIC methodology. Once the project team was formed, they then embarked on scoping the project, identifying improvement opportunities, as well as clarifying the project outlines and goals (Arafeh et al., 2014; Karout and Awasthi, 2017).

\subsubsection{Team Formation}

A team of three people was formed, comprising a senior account executive (responsible for the entire sales process), an experienced front-line sales staff (responsible for the onboarding stage), and an improvement project facilitator. The facilitator served as the project leader to bring SixSigma expertise/improvements. The two employees had basic knowledge about Six-Sigma and were familiar with statistical tools.

The top management of Company XYZ showed a positive involvement in the project, which is crucial for the success of improvement initiatives (Shamsuzzaman et al., 2018) and can multiply the positive effects at all levels in the organisations (Gijo et al., 2019).

\subsubsection{Project Scoping}

The project scoping defines the boundaries and helps concentrate the efforts on the core purpose to adequately achieve the desired results (Patel, 2017). Since the company received a series of complaints from dissatisfied merchants about waiting time in the onboarding process, the research scope was limited only to the onboarding stage of the sales process. The onboarding stage included the activities of issuing registration numbers, calling merchants as per turn, entering data into the system, creating a contract, and placing orders. Moreover, addressing the waiting time issues was of strategic importance for the company as it directly impacted the efficiency of the overall sales activities to expand market share and generate more profit. 


\subsubsection{SIPOC (Supplier-Input-Process-Output-Customer) Diagram}

To obtain a detailed understanding of the process/steps involved, and their flow, to achieve the desired outputs, it is vital to have a clear understanding of the big picture of the process (Pyzdek and Keller, 2014). For this purpose, a SIPOC (Supplier-Input-Process-Output-Customer) diagram was created, as illustrated in Figure 2, to create a high-level map of a process that helps in defining boundaries and identifying processes requiring improvements (Gijo and Scaria, 2014).

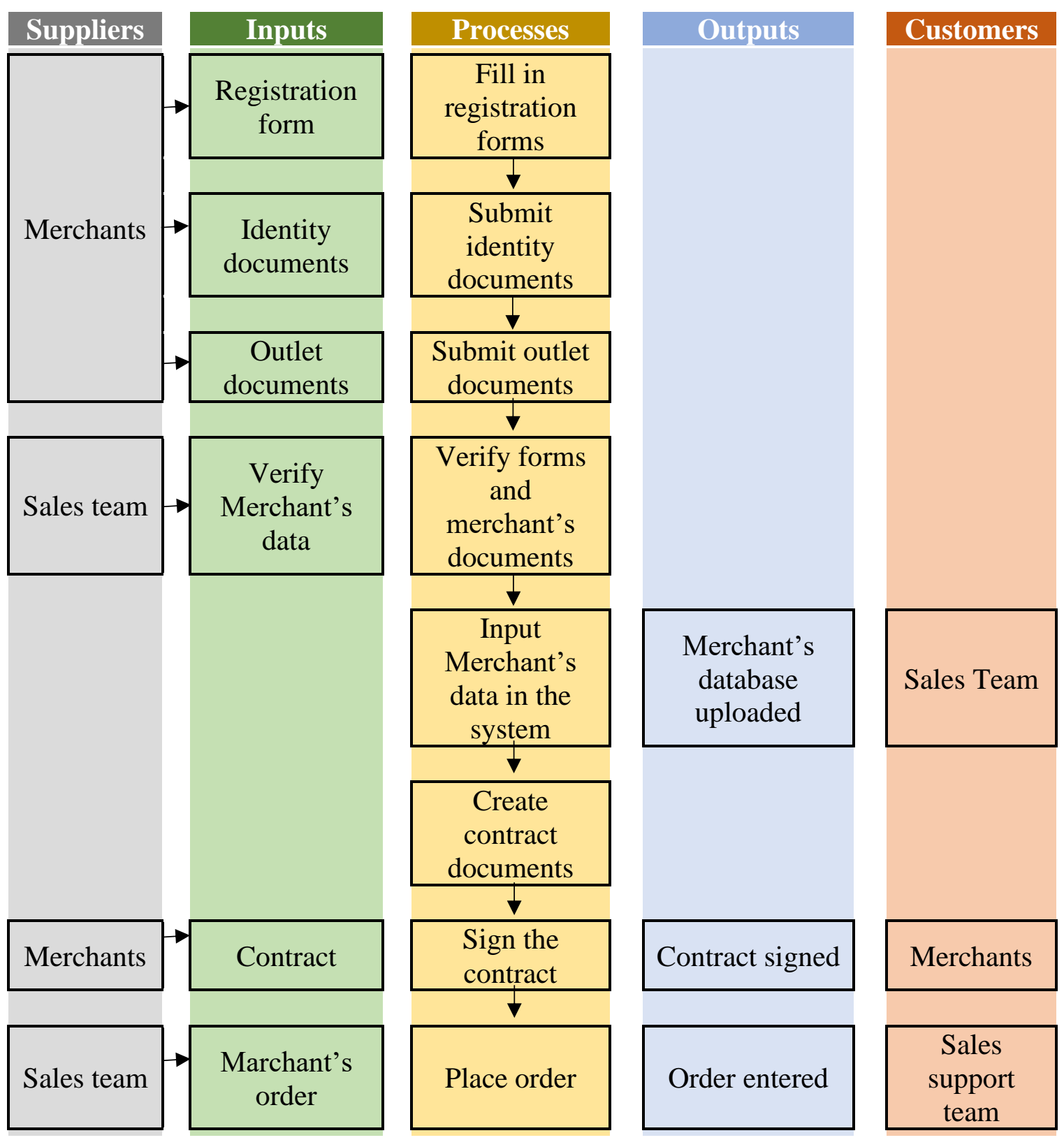

Figure 2. SIPOC diagram for onboarding stage in the sales process. 
As seen in Figure 2, the onboarding stage starts with the front-line staff issuing a registration form/number for merchants. Merchants then fill in the registration form and submit with the identity documents, as well as outlet documents such as food photos, menu details, and menu price. The submitted documents are checked by staff and if all the information provided is adequate, the information is then entered into the system. Following this, a contract is created and given to the related merchant. Finally, the process ends when the merchant signs the contract, and the order is forwarded to the sales support and content division for further processing.

\subsubsection{Operational Definition of Waiting Time}

To investigate the merchant's waiting time issue, it was essential to develop an operational definition for the waiting time. The project team concluded that the time from when the merchant fills in the registration form until the time the merchant signs the contract would be defined as 'merchant waiting time in the onboarding stage'. Consequently, the time when the staff issued the registration number and placed the order to the corresponding division were excluded from waiting time.

\subsubsection{Voice of the Customer}

It is essential to understand customer's needs and perceptions of value to deliver the right products/services (Patel, 2017). For this purpose, Voice of the Customer (VOC) expressing their requirements at all levels (Cudney and Agustiady, 2017) were examined to support the improvement initiatives. This VOC should be translated into specific elements within the process, so the company could identify areas to be improved based on the customers' point of view (Chakraborty and Tan, 2012). These values were indicated as critical to satisfaction (CTS) and had a direct effect on the process output.

The VOC was formulated based on customers' complaints regarding the onboarding process, which were obtained through phone calls, emails, and/or direct visits to them. An increase in customer complaints for the last three months further affirmed the lack of efficiency and effectiveness of this process. Since the complete information regarding the customer complaints history was confidential information, the selected VOC used in this project was derived from the results of meetings with staff which had been approved by the Regional Sales Manager. Next, the VOC was transformed into CTS.

The merchant's waiting time indicated the value in the process that needed to be improved according to the customers' standpoint. As the waiting time could impact the process output, which was the contract, it was considered as CTS and measured by the time from filling in the registration form until signing the contract, which was specified to be 20 minutes. Defect definition was described as the waiting time to be more than 20 minutes.

\subsubsection{Project Goal}

After identifying the problem and defining the CTS, the project team, in consultation with the Regional Sales Manager, formulated the project's goal, which was 'to reduce the merchant waiting time in the onboarding stage to less than 20 minutes'. The 20 minutes target was set based on the requirement of the manager in the company. Additionally, since waiting time problems were also the result of unclear procedures, another goal was 'to create a standardised, documented, and repeatable onboarding process'. 


\subsubsection{Project Charter}

Finally, a project charter was created to capture and summarise all necessary details of the project (Gijo et al., 2014), to constitute the documented conclusion of the Define phase. The project charter presented in Table 1 was used as a guide for the team.

Table 1. Project charter.

\begin{tabular}{|l|l|}
\hline Project Title & \multicolumn{2}{|l|}{ Reducing waiting time in the onboarding stage in the sales process } \\
\hline Business case & $\begin{array}{l}\bullet \quad \text { The onboarding stage is very critical to sales efficiency. } \\
\text { Early onboarding process means faster set up of the platform for the merchants. } \\
\text { Performing a streamlined onboarding process leads to higher customer satisfaction and increases sales } \\
\text { activities that affect the business bottom line. }\end{array}$ \\
\hline $\begin{array}{l}\text { Problem } \\
\text { statement }\end{array}$ & $\begin{array}{l}\text { Customers perceive that they wait too long in the onboarding stage to get the contract. This indicates that there } \\
\text { is a lack of service in this process which results in an increase in customer complaints for the past three months. }\end{array}$ \\
\hline Project scope & The onboarding stage in the sales process \\
\hline Project goals & To reduce waiting time in the onboarding stage to less than 20 minutes \\
\hline Primary metric & Merchant waiting time (minutes) \\
\hline CTS & Merchant waiting time in the onboarding stage \\
\hline Project team & $\begin{array}{l}\text { (i) A senior account executive } \\
\text { (ii) } \quad \text { An experienced front-line staff } \\
\text { (iii) } \quad \text { The researcher }\end{array}$ \\
\hline $\begin{array}{l}\text { Expected } \\
\text { benefit }\end{array}$ & $\bullet \quad \begin{array}{l}\text { Reduction of waiting time in the sales process } \\
\text { Reduction of merchant complaints }\end{array}$ \\
\hline
\end{tabular}

\subsection{The Measure Phase}

The main objective of this phase is to gain a deeper understanding of the baseline performance of the current process by making a necessary measurement (Shamsuzzaman et al., 2018). Merchant waiting time was the primary data collected since it was the main CTS of this project. Afterwards, this data was used to evaluate the current performance of the process through statistical analyses.

\subsubsection{Data Collection}

The waiting time recorded in this research was classified as continuous data (measured in minutes) which meant data that could be recorded as an infinite number with decimal points (Patel, 2017). The data was collected over 11 working days (Monday to Friday), which resulted in a sample of 145 orders being observed (see Appendix A). The sample was considered to be representative of the ongoing process and sufficient to be analysed further as statistical analyses require a minimum of 30 samples to result in a normal distribution. Normally distributed data was significant in this study to ensure that counterfeit results did not occur (Saunders et al., 2016). Furthermore, since the data would be statistically analysed to evaluate the baseline performance (i.e. process capability), the preferred sample size was 100 observations (Montgomery, 2007), thus the data obtained was considered to be adequate for this study.

\subsubsection{The Baseline of the Process}

The baseline of the current process was established by evaluating customer requirements against the current process (Patel, 2017). To do this, process capability was employed since it provided a method to determine how well a process complied with customer expectations (Cudney and Agustiady, 2017). In this project, a process capability analysis of merchant waiting time was conducted to check whether it met the required (i.e., agreed) waiting time. 
Based on this information, a normality test was performed to check the distribution of the waiting time and a control chart was utilised to ensure that the waiting time stayed within control limits (Garza-Reyes et al., 2016). Once these two conditions were fulfilled, a process capability analysis was conducted.

\subsubsection{Normality Test and Control Chart}

The collected data were first tested for normality to determine the distribution of the waiting time. This test was formulated as a hypothesis testing:

$H_{0}: \quad$ The data is normally distributed

$H_{l}$ : $\quad$ The data is not normally distributed

The test was performed at $\alpha=0.05$ or $95 \%$ confidence interval using the Anderson-Darling normality test with the help of Minitab 18 statistical software (see Figure 3). The results indicated that the data was not normally distributed as the $p$-value was less than 0.05 . This means that the null hypothesis was rejected. Consequently, the Box-Cox transformation was tried for transforming the data into normally distributed data. This transformation was chosen because it was the most widely used technique for transforming data in the Six-Sigma approach (Pyzdek and Keller, 2014).

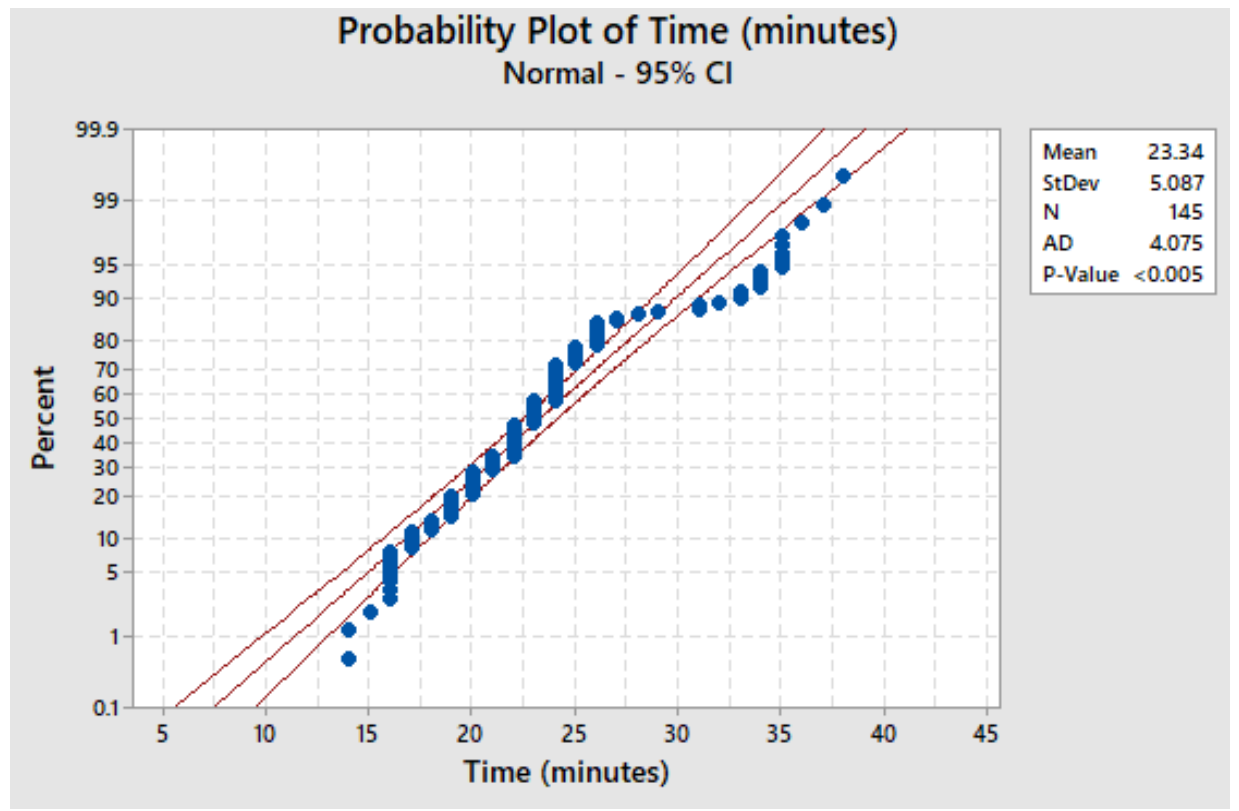

Figure 3. Normal probability plot for waiting time data.

Thereafter, the data were subjected to a control chart to ensure that the process was under statistical control (see Figure 4). Since the sample data in this study was obtained from individual measurement, the I-MR control chart was employed because in such a situation the control chart for individual units was worthwhile (Montgomery, 2007). After having the normally distributed and in statistical control data, the process capability analysis was conducted. 


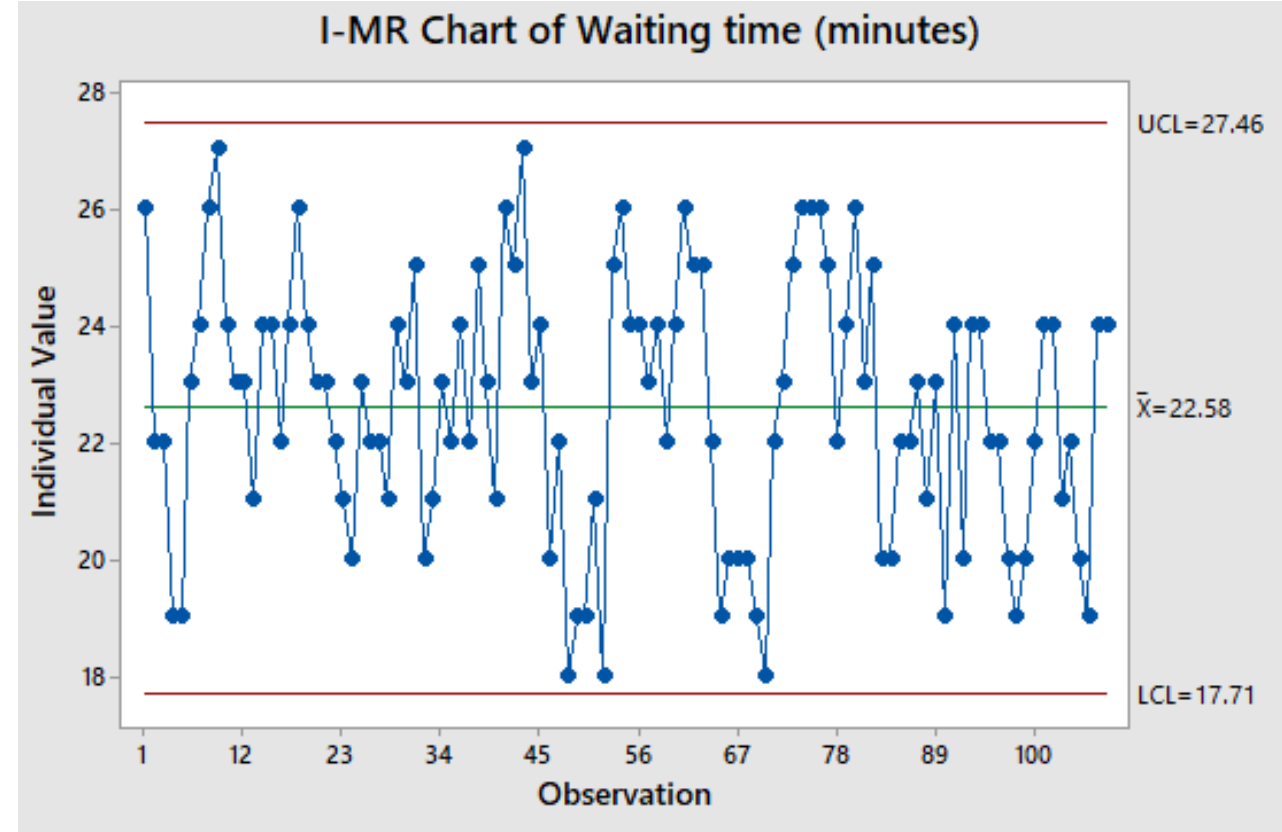

Figure 4. Modified I-MR chart for waiting time data.

\subsubsection{Process Capability Analysis}

Process capability is one of the most common techniques in service organisations to analyse/decide whether the process is capable of meeting requirements (Antony, 2004a; Pyzdek and Keller, 2014). It is expressed using a process capability ratio or "Cpk" value. If the value is lower than 1.33 , the process is not capable of meeting expectations, and if $\mathrm{Cpk}$ is more than 1.33, it can be concluded that the process is capable to fulfil specification limits. Accordingly, the process capability of the transformed waiting time data was computed to discover the actual state of the process as shown in Figure 5.

It was found that the onboarding process was not capable of meeting customer requirements since the index value Cpk was less than 1.33. Moreover, $72 \%$ of the observed data was more than the upper specification limit. This meant that more than half of the waiting time did not meet the agreed specification. This confirmed the long waiting time problem faced by the case organisation and hence suggested that there was a need for improvement in the baseline performance of the process. 


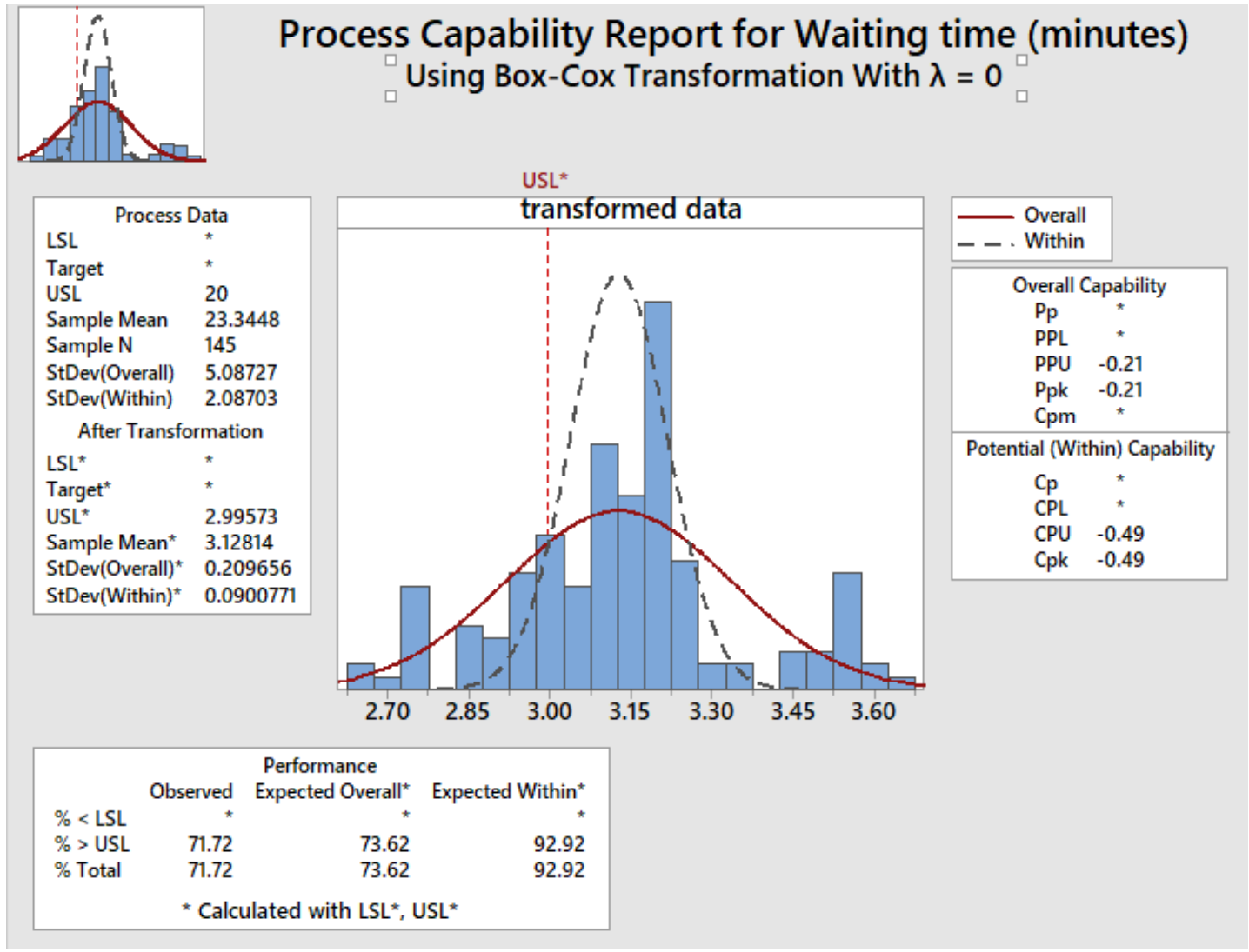

Figure 5. Process capability analysis of transformed waiting time data.

\subsection{The Analyse Phase}

After measuring the onboarding stage, the analyse phase focused on investigating the causes that specified the selected CTS behaviour as well as organising and validating these potential causes (Sin et al., 2015).

\subsubsection{Process Flow Chart of the Onboarding Stage}

A flow chart was prepared to visualise and better understand the detailed steps of the onboarding process sequentially (see Figure 6) as well as empirically confirming the problem faced by the case organisation. During the development of the flow chart, the team identified and listed the NonValue Added (NVA) activities: waiting for the merchant to fill in the registration form and waiting for the merchant to be ready with the required documents. However, in the end, the team agreed to classify these NVA activities into Essential NVA (ENVA) since these were necessary to perform the onboarding stage.

It was then confirmed that the waiting time was the main ENVA, which seemed to appear in the process due to its nature. As a result of the ENVAs, the onboarding stage was getting delayed so that the merchant had to wait longer for the contract to be ready. Thus, the team devised a plan to address these ENVAs during the Improve phase of the study. 


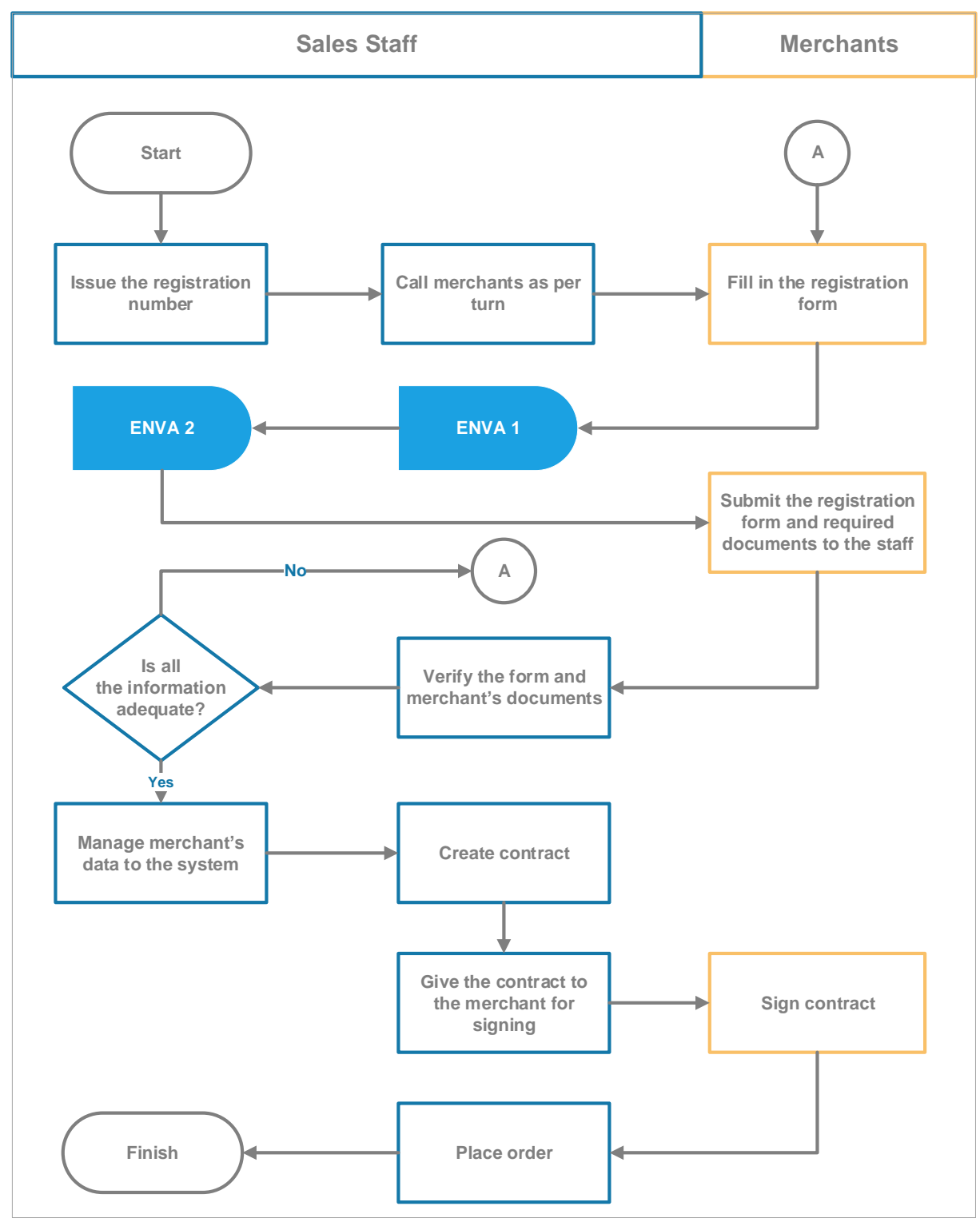

Figure 6. Process flow chart for the onboarding stage.

Furthermore, the team decided to investigate each step identified in the process flow chart (see Figure 6) to identify potential causes for waiting time in the overall onboarding stage. For this purpose, a cause-and-effect analysis was performed.

\subsubsection{Causes and Effect Analysis}

To conduct the cause-and-effect analysis, a brainstorming session to identify all possible causes of waiting time was carried out, by involving all the team members. The brainstorming session drove the team members to exchange and develop ideas with each other (Garza-Reyes et al., 2016), and this resulted in a comprehensive cause-and-effect diagram (see Figure 7). 


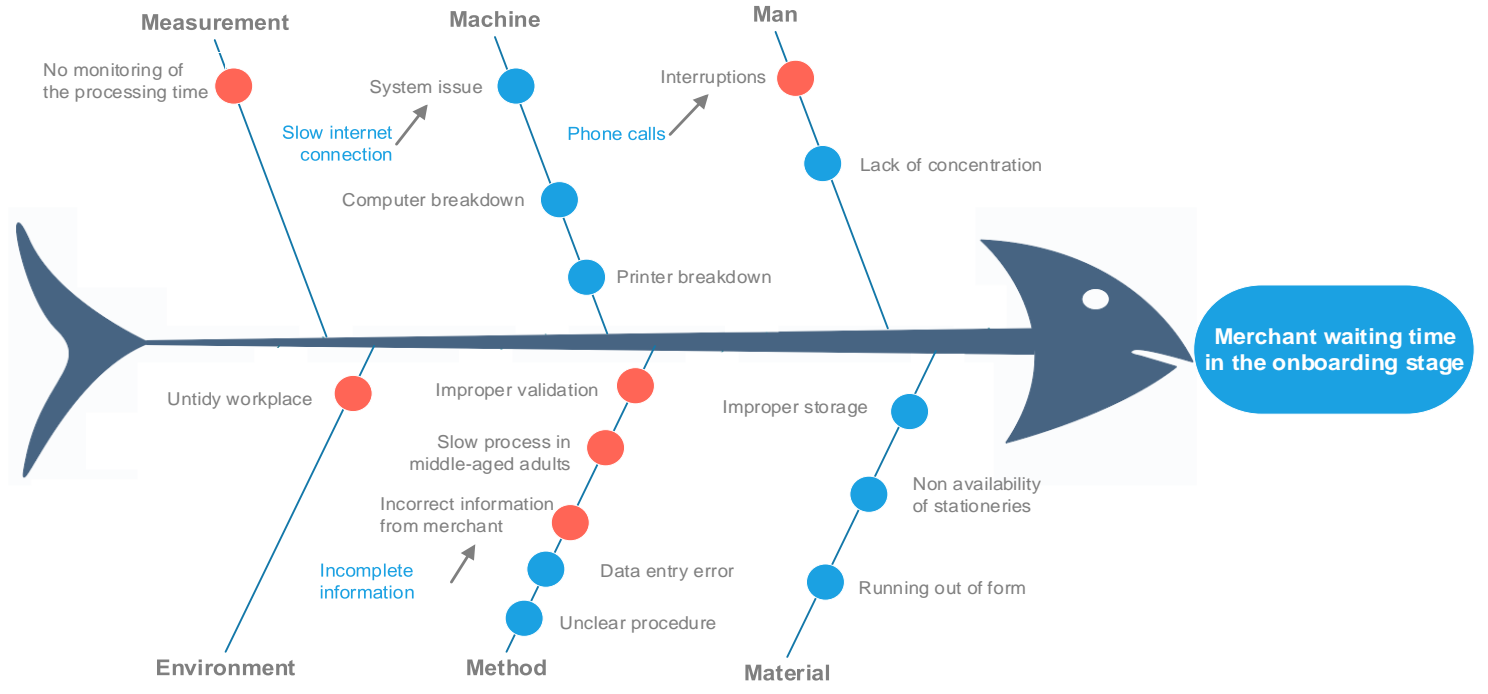

Figure 7. Cause-and-effect diagram for merchant waiting time in the onboarding stage.

It was noticed that around 15 potential causes resulted in merchant waiting time. A plan was prepared to validate potential causes that did not have measurable data. The validation was carried out by observing the process for a specific period to decide whether the cause was a root cause or not. This validation through observation is generally termed as Gemba walk. On the other hand, for the potential causes which had measurable data, the validation was carried out using hypothesis testing. With all these details, the validation plan outlined in the third column of Table $2 \mathrm{~B}$ was prepared for all the listed causes in the cause-and-effect diagram (Figure 7).

\subsubsection{Cause Validation using Gemba Investigation}

The project team repeatedly observed the process concerning these causes, for one week. Afterwards, the presence and the absence of the causes were recorded, and a decision was taken to characterise whether it was a root cause or not, referring to the frequency of potential causes that occurred during the observation. The results of the Gemba observation are provided in Table $2 \mathrm{~B}$.

\subsubsection{Cause Validation using Statistical Analysis}

According to the plan given in Table $2 \mathrm{~A}$, each potential cause that needed to be validated using statistical techniques was provided as follows.

\section{Lack of Concentration}

Compared to other sales activities, the onboarding stage consisted of many routine tasks which made the staff feel bored and difficult to concentrate. Based on information obtained from the staff, they perceived that their performance tended to decline after taking the lunch break. Therefore, it was agreed to validate "lack of concentration" by finding out whether there was a significant difference in onboarding duration (minutes) before and after lunch break (before and after $1 \mathrm{pm}$ ) by collecting data for a week. To do this, the following hypotheses were formulated:

$H_{0}: \mu$ before $1 \mathrm{pm}=\mu$ after $1 \mathrm{pm}$

$H_{1}: \mu$ before $1 \mathrm{pm} \neq \mu$ after $1 \mathrm{pm}$ 
Before continuing further, it was necessary to conduct a normality test first so that the appropriate test procedure could be followed (Montgomery, 2007). This data was tested using the AndersonDarling normality test (see Figure 8). The result showed that the data was normally distributed because the $p$-value for both data was greater than 0.05 .

As the assumption of normality was met, and the data consisted of two independent samples, a twosample $t$-test analysis was carried out. Before performing this test, it was necessary to test the equality of variances of the two populations, so that an $F$-test was conducted for this purpose. The results of these tests are provided in Table $2 \mathrm{~A}$.

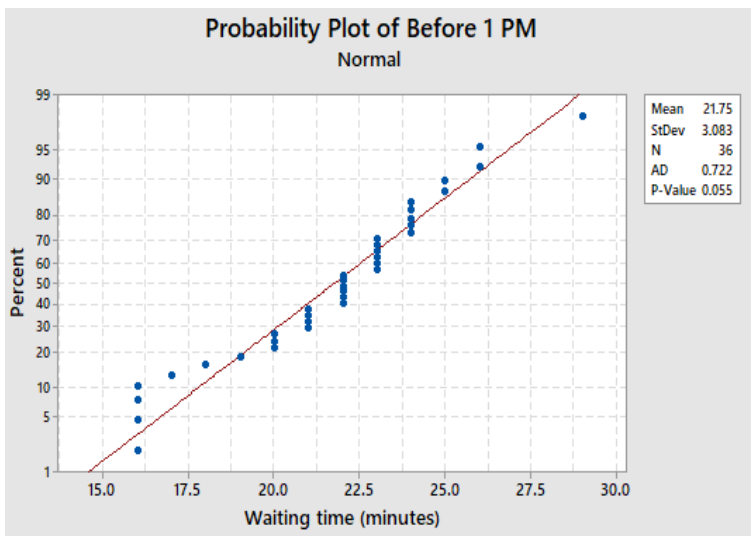

(a)

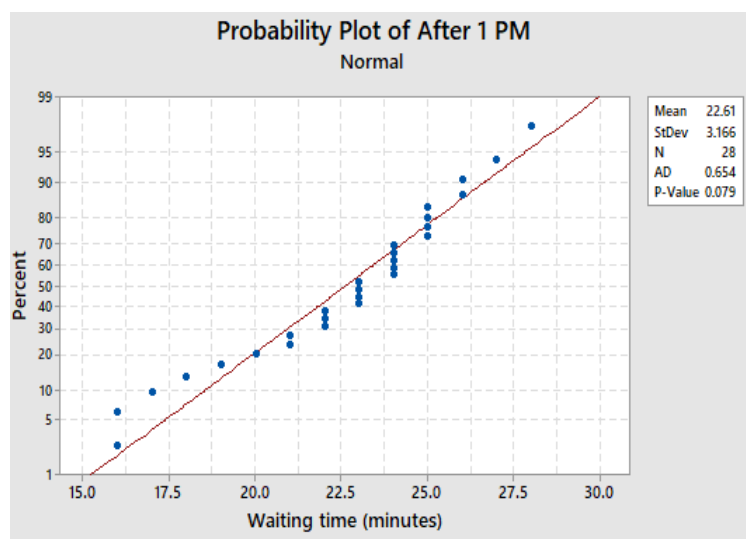

(b)

Figure 8. Probability plot for the onboarding process before $1 \mathrm{pm}$ (a) and after $1 \mathrm{pm}$ (b).

Table 2. Hypothesis test results.

\begin{tabular}{|c|c|c|c|}
\hline \multicolumn{4}{|c|}{ A) For lack of concentration } \\
\hline \multirow{2}{*}{$F$-test } & $F$-value & $F$-critical & Conclusion \\
\hline & 1.05 & 1.86 & Equal variance \\
\hline Potential cause & $t$-value & $t$-critical & Conclusion \\
\hline $\begin{array}{l}\text { Less concentration - variation between } \\
\text { onboarding duration (minutes) before and after } \\
\text { lunch break (before and after } 1 \mathrm{pm} \text { ) }\end{array}$ & -1.09 & 1.99 & $\begin{array}{l}\text { Fail to reject } \mathrm{H}_{0} \text { : There was no significant difference } \\
\text { between the onboarding process before and after } 1 \\
\text { pm }\end{array}$ \\
\hline \multicolumn{4}{|c|}{ B) For incorrect information from the merchant } \\
\hline Potential cause & \multicolumn{2}{|c|}{ Asymp. Sig. (2 tailed) } & Conclusion \\
\hline Inaccurate information from the merchant & \multicolumn{2}{|c|}{0.007} & $\begin{array}{l}\text { Reject } \mathrm{H}_{0} \text { : There was a significant difference in the } \\
\text { onboarding process between merchants with an } \\
\text { accurate response and inaccurate response }\end{array}$ \\
\hline \multicolumn{4}{|c|}{ For the slow process in middle-aged adults } \\
\hline Potential cause & \multicolumn{2}{|c|}{ Asymp. Sig. (2 tailed) } & Conclusion \\
\hline $\begin{array}{l}\text { Slow process in middle-aged adults ( } 36-64 \text { years } \\
\text { old) }\end{array}$ & \multicolumn{2}{|c|}{0.000} & $\begin{array}{l}\text { Reject } \mathrm{H}_{0} \text { : There was a significant difference in the } \\
\text { onboarding process between merchants less than and } \\
\text { more than } 35 \text { years old }\end{array}$ \\
\hline
\end{tabular}

Based on the results, the t-value was less than t-critical, hence it was concluded that there was no significant difference in the onboarding process before and after $1 \mathrm{pm}$. As a result, the lack of concentration was not included as a root cause of merchant waiting time. 


\section{Incorrect Information from Merchant}

When filling the registration form, the merchant was required to submit identity documents such as a copy of the national identity card, passbook, and taxpayer identification number. These documents were checked by staff to find out whether the information provided was accurate. If the information provided was inaccurate, the staff would ask the merchant to correct the data, which usually took time as the staff should explain again and wait for the updated information to be submitted. Consequently, the time needed to process the merchant who provided the correct information and the merchant who needed to revise the information would be different, hence became one of the potential causes of the problem. For this reason, it was decided to validate this condition by comparing whether there was a significant difference in onboarding duration (minutes) for each case. A hypothesis test was also designed to investigate this cause to test.

\section{$H_{0}: \mu$ accurate response $=\mu$ inaccurate response}

$H_{1}: \mu$ accurate response $\neq \mu$ inaccurate response

The collected data were tested for normality test (see Figure 9). It indicated that the data from the merchant who provided the correct information was not normally distributed as the $p$-value was less than 0.05. Nevertheless, since the $p$-value for the merchant who needed to revise the information was 0.307 , greater than 0.05 , the null hypothesis was accepted, indicating that the data for this type of merchant was normally distributed. Based on these results, it could be seen that the assumption in the parametric test was not fulfilled since one of the group data was not normally distributed. Therefore, a non-parametric test using the Mann-Whitney test was conducted. The test's result is presented in Table $2 \mathrm{~B}$.

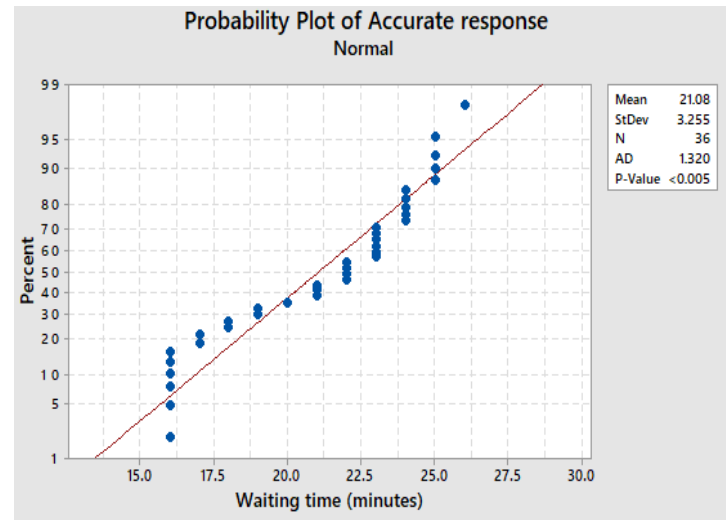

(a)

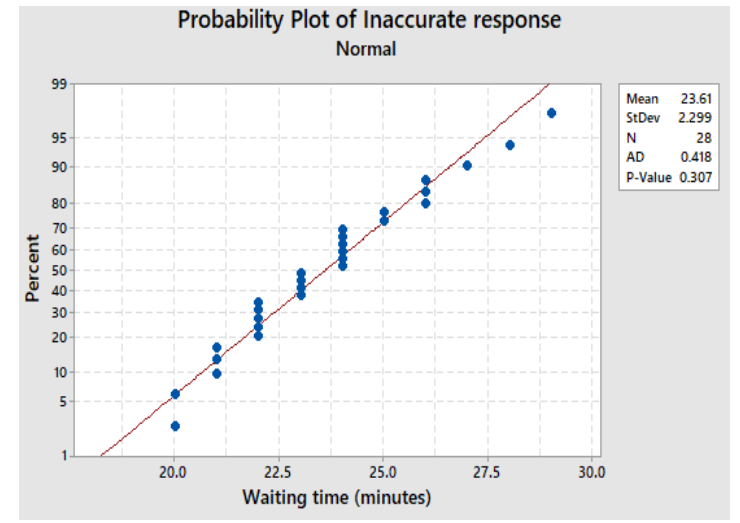

(b)

Figure 9. Probability plot for the onboarding process with accurate response (a) and inaccurate response (b).

Based on the result obtained, it was concluded that there was a significant difference in the onboarding process between merchants with accurate and inaccurate responses. As a result, incorrect information was considered as a root cause of merchant waiting time and thus it was analysed further in the Improve phase (Section 5.4). 


\section{Slow Process in middle-aged Adults}

The project team observed, with further confirmation from the case company, that merchants over the age of 35 years faced difficulty in following the process as they often were either not sure of the outlet's information or even forgot and provided wrong information without realising how crucial it was to have accurate information such as address and other details of their products/offerings. Consequently, variation in merchant waiting time occurred with middle-aged merchants (36 to 64 years).

To validate this cause, data were collected individually in the onboarding process from merchants younger and older than 35 years. A hypothesis test was formulated to test this cause.

$H_{0}: \mu$ less than 35 years old $=\mu$ more than 35 years old

$H_{1}: \mu$ less than 35 years old $\neq \mu$ more than 35 years old

Data were analysed using a normality test as illustrated in Figure 10. It was seen that all the $p$ values were smaller than 0.05 for it to be considered as a not normal distribution. Therefore, a nonparametric test was used and according to the Mann Whitney test results (see Table 2C), there was a significant difference between the onboarding process for merchants less than and more than 35 years old. Therefore, the slow process in middle-aged adults was considered as another of the root causes.

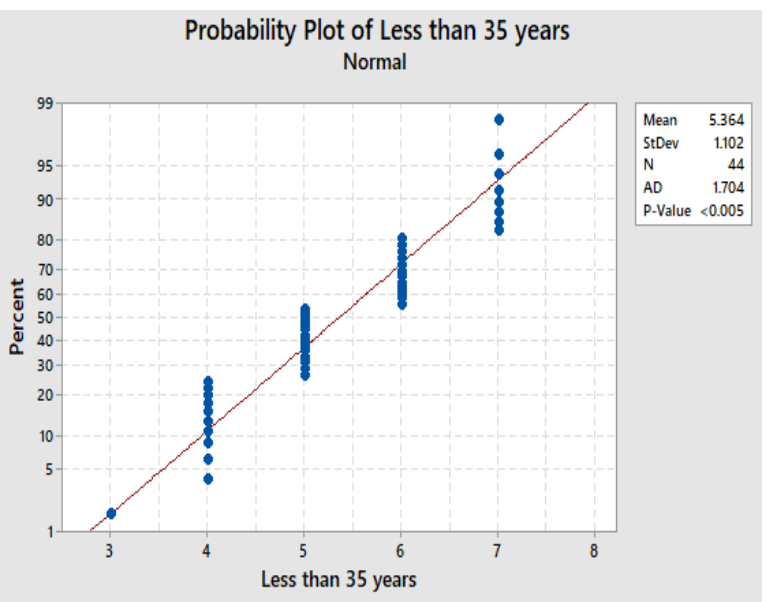

(a)

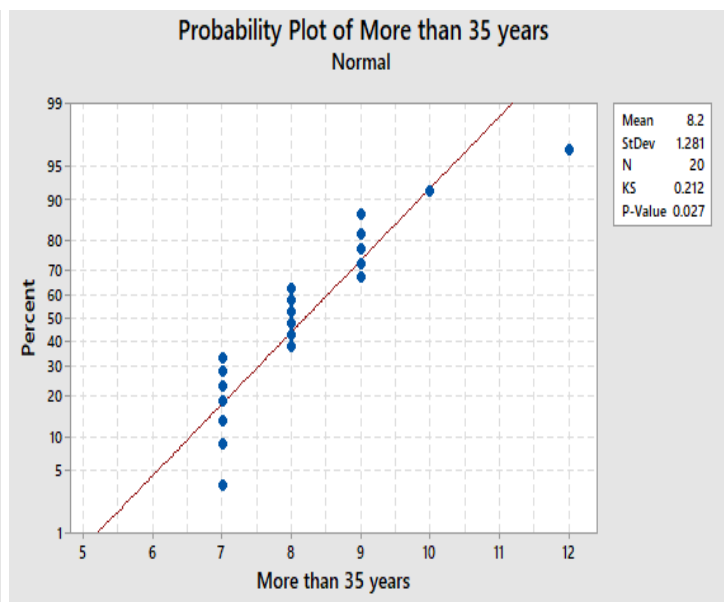

(b)

Figure 10. Probability plot for the onboarding process for merchants less than 35 years old (a) and more than 35 years old $(b)$.

After investigated all the potential causes as per the plan, the summary of validated results is presented in Table 3, and the solutions for these root causes were devised during the Improve Phase (see Section 5.4) of this project. 
Table 3. Details of cause validation.

\begin{tabular}{|c|l|l|l|l|}
\hline No & Cause & Validation method & Remarks & Conclusion \\
\hline $\mathbf{1}$ & Interruptions & Gemba Investigation & Observed 17 times during week study & Root cause \\
\hline $\mathbf{2}$ & Lack of concentration & $\begin{array}{l}\text { F-test, independent } \\
\text { two-sample } \text {-test }\end{array}$ & There was no significant difference & Not a root cause \\
\hline $\mathbf{3}$ & System issue & Gemba Investigation & $\begin{array}{l}\text { Observed three times during week } \\
\text { study }\end{array}$ & Not a root cause \\
\hline $\mathbf{4}$ & Printer breakdown & Gemba Investigation & Not observed during week study & Not a root cause \\
\hline $\mathbf{5}$ & Computer breakdown & Gemba Investigation & Not observed during week study & Not a root cause \\
\hline $\mathbf{6}$ & No monitoring of the processing time & Gemba Investigation & Observed 16 times during week study & Root cause \\
\hline $\mathbf{7}$ & Non-availability of stationeries & Gemba Investigation & Not observed during week study & Not a root cause \\
\hline $\mathbf{8}$ & Improper storage & Gemba Investigation & Not observed during week study & Not a root cause \\
\hline $\mathbf{9}$ & Running out of form & Gemba Investigation & Not observed during week study & Not a root cause \\
\hline $\mathbf{1 0}$ & Improper validation & Gemba Investigation & Observed 15 times during week study & Root cause \\
\hline $\mathbf{1 1}$ & Slow process in middle-aged adults & Mann-Whitney test & There was a significant difference & Root cause \\
\hline $\mathbf{1 2}$ & $\begin{array}{l}\text { Incorrect information from the } \\
\text { merchant }\end{array}$ & Mann-Whitney test & There was a significant difference & Root cause \\
\hline $\mathbf{1 3}$ & Data entry errors & Gemba Investigation & Observed once during week study & Not a root cause \\
\hline $\mathbf{1 4}$ & Unclear procedure & Gemba Investigation & Observed 18 times during week study & Root cause \\
\hline $\mathbf{1 5}$ & Untidy workplace & Gemba Investigation & Observed twice during week study & Not a root cause \\
\hline
\end{tabular}

\subsection{The Improve Phase}

Based on the previous DMAIC phases and the results obtained from the various analyses conducted in such phases, this stage aims to generate solutions for root causes that are identified in the analysis phase and it is expected to improve process performance (Shamsuzzaman et al., 2018). For this purpose, two brainstorming sessions were organised. During the first one, the internal project team generated solution ideas for each of the root causes and in the second session these were further discussed with the content staff, sales supervisor, and managers to ensure their input/agreement with the proposed solutions. As a result, six solutions were identified as improvement suggestions. However, due to the time constraint and an unexpected event in the company, these solutions were not rolled out during the time of this research. For this reason, an improvement implementation plan with all necessary details was developed so the management and staff of company XYZ could deploy the plan in the near future. The suggested solution for the ENVA of waiting for the merchant to fill in the registration form was for the form to be provided by the security staff before the merchant reached the registration desk. Another solution consisted of the merchant being ready with the required documents to have the food photos and menu details submitted beforehand. The root causes of the cause-and-effect diagram are outlined in Table 4. Also, these solutions are shown as follows:

(i) Assigning new roles for the security staff.

(ii) Renewing outlet documents submission policy.

(iii) Opening internship opportunities.

(iv) Creating an issue log.

(v) Designing a video-based training.

(vi) Complying a fixed procedure.

In agreement with the company, the solutions were set in order of priority and an implementation roadmap was formulated as a guide for the firm (see Figure 11). The roadmap plan is expected to keep the company focus on the things that matter, thereby the solution can be executed efficiently and effectively. 
Table 4. Identified solutions for root causes.

\begin{tabular}{|c|c|c|c|}
\hline \multicolumn{4}{|c|}{ No / Root Cause / Brief description / Solution } \\
\hline 1 & Interruption & $\begin{array}{l}\text { Frontline staff was interrupted to answer } \\
\text { phone calls and handle questions regarding } \\
\text { the invalid documents }\end{array}$ & $\begin{array}{l}\text { 1. Hire interns to handle the phone calls, thus freeing the } \\
\text { frontline staff to focus on the onboarding process. } \\
\text { 2. Ensure the merchant in the onboarding process } \\
\text { submitting the accurate documents before forwarding } \\
\text { them to the sales support and content division }\end{array}$ \\
\hline 2 & $\begin{array}{l}\text { No monitoring } \\
\text { of the processing } \\
\text { time }\end{array}$ & $\begin{array}{l}\text { There were no clear policies of the onboarding } \\
\text { process, so the staff did not pay attention when } \\
\text { some merchants were processed longer than } \\
\text { others }\end{array}$ & $\begin{array}{l}\text { Create an issue } \log \text { as a tool to record all the special cases } \\
\text { and necessary issues in the process, and thus the } \\
\text { awareness to monitor the processing time is increased }\end{array}$ \\
\hline 3 & $\begin{array}{l}\text { Improper } \\
\text { validation }\end{array}$ & $\begin{array}{l}\text { The staff asked the merchant to revise their } \\
\text { information after it has been entered into the } \\
\text { system }\end{array}$ & $\begin{array}{l}\text { 1. Provide training to enhance the skills and abilities to } \\
\text { do the work per the established standard procedures, } \\
\text { including how to properly validate the merchant's data } \\
\text { 2. Initial document check to be done by the security staff } \\
\text { to reduce the possibility of errors during validation }\end{array}$ \\
\hline 4 & $\begin{array}{l}\text { Incorrect } \\
\text { information from } \\
\text { the merchant }\end{array}$ & $\begin{array}{l}\text { The merchant provided inappropriate } \\
\text { information in the registration form or } \\
\text { submitted inaccurate supporting documents }\end{array}$ & $\begin{array}{l}\text { Trian Security staff to check documents to reduce the } \\
\text { possibility of submitting inaccurate documents }\end{array}$ \\
\hline 5 & $\begin{array}{l}\text { Slow process in } \\
\text { middle-aged } \\
\text { adults }\end{array}$ & $\begin{array}{l}\text { These merchants find it difficult to follow the } \\
\text { process since often they are not sure how to } \\
\text { inform the address through google maps or } \\
\text { even forgot and never noticed the importance } \\
\text { of detailed address }\end{array}$ & $\begin{array}{l}\text { Hire interns to take over an "unintended event" primarily } \\
\text { to assist the middle-aged merchant in completing the } \\
\text { outlet information }\end{array}$ \\
\hline 6 & $\begin{array}{l}\text { Unclear } \\
\text { procedure }\end{array}$ & $\begin{array}{l}\text { The staff usually adjusted the process with the } \\
\text { merchants' readiness and hence the process } \\
\text { became unclear }\end{array}$ & $\begin{array}{l}\text { Comply with the fixed procedure, finish the work } \\
\text { sequentially and avoid repeating the processes. }\end{array}$ \\
\hline
\end{tabular}

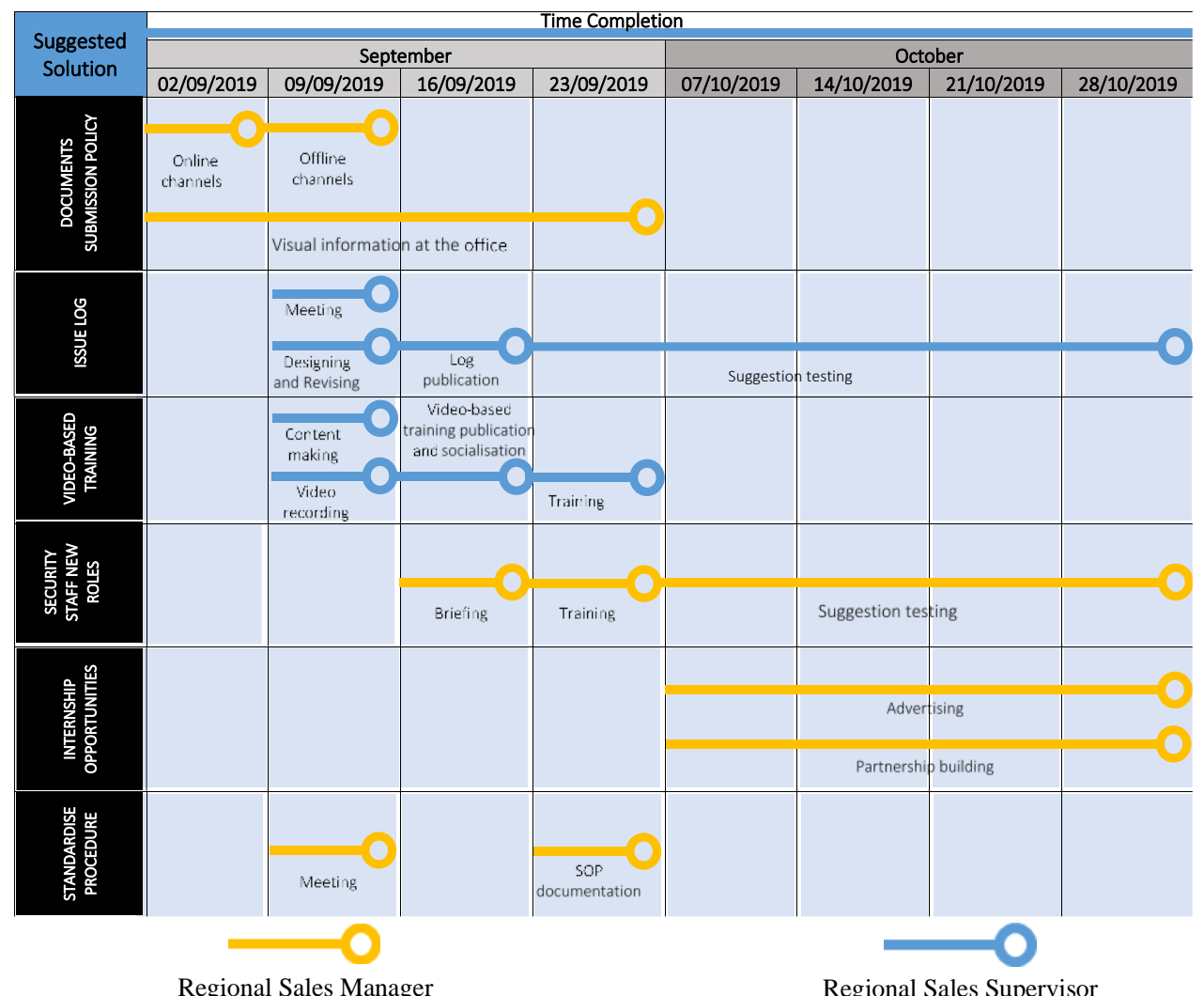

Figure 11. Roadmap plan. 


\subsection{The Control Phase}

This last phase of DMAIC aims to monitor the process so it would sustain and remain under control (Karout and Awasthi, 2017). Like the Implementation phase, the Control phase has not yet been conducted during the time of this study. Hence, suggestions related to the control mechanisms were proposed to the company. In this project, the tools introduced as a control mechanism were Pokayoke, Standard Operational Procedure (SOP), and Control Chart. The reason to adopt these tools is discussed in the following sub-sections.

\subsubsection{Poka-yoke}

This tool is used to prevent unintentional errors from happening and/or from being repeated. There are two approaches used in this technique; the first is a control system, a mechanism used to stop the next process when unexpected errors occur; and the second is the warning system, a mechanism providing alerts or signals to prevent errors (Cudne and Agustiady, 2017). In addition, Poka-yoke can help to minimise the faults caused by human factors like lack of concentration, carelessness, forgetfulness, and misunderstanding (Kuvvetli and Firuzan, 2019). Since the identified root causes are of such nature, this solution would assist merchants and staff to be ready for an efficient and effective onboarding process by creating mistake-proofing strategies as follows:

- No merchant goes through the onboarding stage with invalid documents. Hence, the security staff would review the required documents before giving the registration form to merchants.

- The merchant's information cannot be entered into the system without all mandatory information and submitted attachments (i.e., food photos and menu details).

\subsubsection{Standard Operational Procedure (SOP)}

This document ensures that the activities performed are consistent over time and thus help reduce process variation (Patel, 2017). This, in turn, not only increases productivity in the workplace but also minimises the possibility of missed steps that can impact the quality of delivered products and services.

It was noted that company $\mathrm{XYZ}$ did not have a clear set of procedures to perform/complete the onboarding stage. Based on this situation, it was suggested that all the modifications in the process as a part of the improvement are documented through SOP. The SOP document contained consolidating work instructions for the onboarding stage, provisions in merchant services and support, and rules in filling the issues log. Afterwards, the newly established SOP was informed in two ways, the first one was printed on a banner and displayed at the workplace as a visual source of information. The second was published in the knowledge base of the company so that all divisions could access it.

\subsubsection{Control Chart}

The control chart assisted the team in recognising whether the processes stayed within processing time limits. This helped the company to pay attention to the processes and ensure that improvements made were stable over some time (Arafeh et al., 2014). Moreover, the information in the chart helped to distinguish between common and special causes of variations (Kuwaiti and Subbarayalu, 2017). Accordingly, once the causes are identified, necessary preventive actions can be taken to minimise these variations and improve the process. 
The front-line staff were given the responsibility to record the onboarding time for each merchant and plotted the data on the control chart daily. The template for the control chart was prepared as a part of the issue log. Figure 12 was created to depict an instance of a control chart within and outside control limits respectively. This illustration can become a clue for the company to utilise the control chart as the monitoring tool.

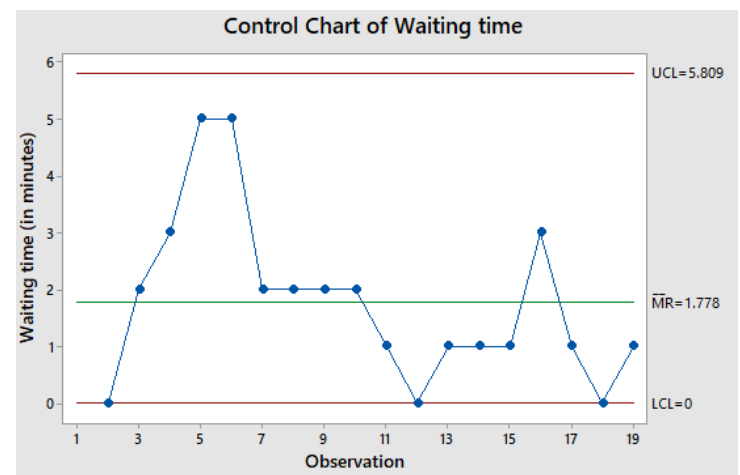

(a)

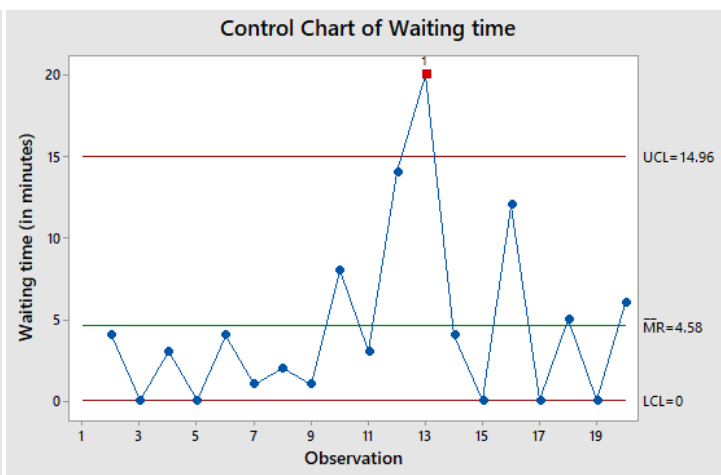

(b)

Figure 12. Control chart without special cause variation (a) and with special cause variation (b).

In addition to this tool, a cause-and-effect diagram can be employed as a guideline in the brainstorming session to identify the root causes of the special causes discovered from the control chart, or a prioritisation matrix can be employed to examine which causes will be tackled first. Afterwards, it was also suggested to administer surveys after the pilot run to measure employees' perception of the merchant waiting times post-improvement. Along with these mechanisms, organising a retrospective meeting to reflect on the results as well as to discuss difficulties and what needs to be improved were also advised.

\section{Discussion and Managerial Implications}

This study presents the deployment of Six-Sigma to reduce the waiting time in the sales process of a Technology-based Start-up company in Indonesia. Scholarly research presented earlier confirms that Six-Sigma implementation in transactional processes such as sales has proven to be challenging due to the difficulty to identify appropriate projects due to fewer process variables that can be controlled (Madhani, 2017). This research builds on previous research by focusing on/appreciating customer needs, by adopting the VOC tool, and effectively drive the team to select the right project; thereby contributes as one of the empirical evidences of Six-Sigma application in the sales area.

Furthermore, the systematic Six-Sigma approach of the DMAIC framework provided an effective and efficient method for the case company to improve sales activities. The selection of the relevant and specific tools, such as a cause-and-effect diagram to analyse the potential causes of the problem and Gemba investigation to validate these causes, facilitated the project team in developing their creativity to solve the problem from a different standpoint. This finding is in line with Madhani (2017) study, which remarks that instead of suppressing creativity and lateral thinking in sales, the deployment of the Six-Sigma structured approach provides a process and framework to channel creative thinking. Therefore, the research demonstrates that the proposed Six-Sigma business improvement approach gives robust and structural guidance that can be adopted by the case company to minimise the merchant waiting time in the sales process. In sum, this study is in line 
with the studies developed by Li et al. (2019), Muralidharan and Raval (2020) and Gijo et al. (2019) as this project helped to improve the process.

Although this study shows fruitful results, it is not free of implementation challenges, specifically in the case of implementing the suggested solutions in the company. The least preferred improvement change, which is asking the staff to comply with a standard procedure, denotes that the sales staff found it difficult to follow the standard procedure to perform their job. This may be considered an inherent nature as previously indicated, the entrepreneurial atmosphere in sales typically resists standardised processes (Madhani, 2017). To overcome this challenge, top management in the company were convinced by referring to examples of some successful standard procedures implementation that had improved process efficiency.

As in many other studies, in this research, it was observed that the key success factor for Six-Sigma deployment was the collaboration between different departments (Kumar et al., 2019; Upadhyay et al., 2021). It was seen that conducting the brainstorming sessions and observing the workplace by involving not only the salespeople but also the security and the staff in the content division has enhanced the utilisation of the Six-Sigma tools in analysing the root causes of the waiting time issue and generating improvement ideas to tackle the problem. Additionally, the support of the Regional Sales Manager during the project also contributed to the successful Six-Sigma implementation in the company. These findings are consistent with earlier studies by Madhani (2017) and Shamsuzzaman et al. (2018), affirming the need for removing departmental silos and actively engaging the senior management to achieve the desired outcomes by applying Six-Sigma. Since the implementation of Six-Sigma in the case company was novel, the project motivated employees as the company became a data-driven business that also applied statistical measurement and control as a vital value for decision making. Since Six-Sigma mainly relies on data and facts, its nature conformed with the inherent culture in the case company. This helped employees in the project team to take ownership of the project as well as to encourage other employees to embrace the Six-Sigma concept as one of the improvement journeys for the company. As a result of this project, the employees gained new knowledge on Six-Sigma and were also better equipped to initiate further improvements.

Finally, the aforementioned findings have several practical implications. Firstly, the successful execution of this project allowed employees to adopt this methodology extensively and enabled them to improve more complex business processes in forthcoming projects, either in the sales or other departments. Secondly, this study remarks how the employees involved in this project were able to analyse problems, using simple statistical tools, and thus made scientifically based decisions instead of intuitional decisions. Thirdly, this can trigger interest among other technology start-ups to adopt Six-Sigma as a vehicle for business improvement and gain competitiveness. Other firms can find this study valuable as it offered a specific approach and an easy-to-use replicable roadmap for improving processes in a similar context. This may guide them to implement different SixSigma tools and techniques that are relevant to their specific needs/case. Concluding, the results of this research also give support to other industrial sectors and practitioners to deploy Six-Sigma as business improvement initiatives in business functions.

\section{Conclusions, Limitations and Future Research Directions}

An action research study-based was conducted to map the scope of Six-Sigma in the sales function of a technology start-up company. Multiple Six-Sigma tools were deployed by utilising the DMAIC 
approach. Once the research project was delivered, it was found that Six-Sigma facilitated a clear and systematic approach to assist the company in reducing merchant waiting time.

Firstly, an extensive literature review provided a profound understanding associated with the theoretical concept of some Six-Sigma principles and tools and their application. Then the current sales process of the company XYZ was analysed, and it was identified that the onboarding stage in the sales process experienced the problem of long waiting time for customers. To address the issue, the DMAIC cycle and several Six-Sigma tools were utilised for data analysis and helping the company to identify its root causes. To deal with those root causes, a set of six solutions were suggested to the company along with an implementation roadmap to guide the company's management and employees for the effective implementation of the suggested solutions. The successful deployment of Six-Sigma principles and tools to reduce waiting time in the sales process of a technology start-up company in Indonesia is considered as evidently fulfilled.

This research does have some limitations that restrict the wide-scale generalisability of this research. First, Six-Sigma applications to sales function are not common, therefore, there are only a few prior research studies that can be referenced regarding Six-Sigma applications in the sales area. Second, due to unexpected circumstances, the Improve and Control phases were not rolled out during the time of the study. However, a list of suggested solutions and an implementation roadmap led to the conclusion that there would be improvements made in the process. Based on this consideration, the study was restricted to the aim of deploying Six-Sigma principles and tools to reduce waiting time by proposing an implementation roadmap. Third, the results presented in this article are based on a single organisation, which provides a limited sample to understand the applicability of Six-Sigma to reduce waiting time in the sales process of a technology start-up company. Hence, a generalisation of these results is not advised from a single case, and specifically to other types of industries. Fourth, according to company XYZ's practitioners, the waiting time produced in the onboarding stage was the main issue to be solved applying the Six-Sigma method. Nevertheless, the waiting time issue may also depend on other contextual conditions that are internal and external to the firm under analysis (Dieste et al., 2020). Fifth, data was collected in 11 working days. This interval may be considered short; nevertheless, it provided enough observations to carry out the study.

This action research study is among the first initiatives to show how Six-Sigma principles and tools can be deployed in a technology start-up company in Indonesia. In addition, extant studies have often neglected Six-Sigma applications in the transactional process as illustrated in this project. Hence, the novelty of this article lies in the fact that it contributes to filling this research gap and adds to the body of knowledge with a clear Six-Sigma application example in a start-up company. In other words, the findings of this study advance the limited research and evidence of Six-Sigma application in the transactional process and specify the Six-Sigma framework as directions to progress future research in this area.

In the future, further studies can focus on the next stage of the sales process in the company. Procedures to explore this stage can be executed similarly to this research by employing the systematic approach of Six-Sigma methodology (DMAIC) and utilising appropriate statistical and improvement tools. Moreover, further studies are still needed on exploring more case studies regarding the application of Six-Sigma in start-up companies, not only in Indonesia but also in other countries. This will contribute to the body of knowledge since a research gap exists around using Six-Sigma for business improvement in such areas. The outputs of the study can be a source 
for the comparison of the success rate of Six-Sigma application in various processes across different types of start-ups. Furthermore, topics of study may include the creation of a specific framework to implement DMAIC Six-Sigma in sales processes and to recommend statistical tools employed in Six-Sigma for its implementation. Future research may apply these ideas, thereby can prove helpful in understanding the potential of the Six-Sigma application for different industries, including start-up companies.

Conflict of Interest

The authors confirm that is no conflict of interest to declare for this publication.

Acknowledgements

This work was supported by the "Seedcorn fund" provided by the University of Derby (UK).

\section{References}

Alblooshi, M., Shamsuzzaman, M., Khoo, M.B.C., Rahim, A., \& Haridy, S. (2020). Requirements, challenges and impacts of Lean Six Sigma applications - a narrative synthesis of qualitative research. International Journal of Lean Six Sigma, 12(2), 318-367.

Alkunsol, W.H., Sharabati, A.A.A., AlSalhi, N.A., \& El-Tamimi, H.S. (2019). Lean Six Sigma effect on Jordanian pharmaceutical industry’s performance. International Journal of Lean Six Sigma, 10(1), 2343.

Antony, J., Sony, M., \& Gutierrez, L. (2020). An empirical study into the limitations and emerging trends of six sigma: findings from a global survey. IEEE Transactions on Engineering Management, 1-14. https://doi.org/10.1109/TEM.2020.2995168

Antony, J. (2004a). Six Sigma in the UK service organisations: results from a pilot survey. Managerial Auditing Journal, 19(8), 1006-1013.

Antony, J. (2004b). Some pros and cons of six sigma: an academic perspective. The TQM Magazine, 16(4), 303-306.

Antony, J. (2006). Six sigma for service processes. Business Process Management Journal, 12(2), $234-248$.

Antony, J., Gijo, E.V., Kumar, V., \& Ghadge, A. (2016). A multiple case study analysis of Six Sigma practices in Indian manufacturing companies. International Journal of Quality \& Reliability Management, 33(8), 1138-1149.

Arafeh, M., Barghash, M.A., Sallam, E., \& AlSamhouri, A. (2014). Six Sigma applied to reduce patients' waiting time in a cancer pharmacy. International Journal of Six Sigma and Competitive Advantage, 8(2), 105-124.

Baker, T., \& Jayaraman, V. (2012). Managing information and supplies inventory operations in a manufacturing environment. Part 1: An action research study. International Journal of Production Research, 50(6), 1666-1681.

Ben Ruben, R., Vinodh, S., \& Asokan, P. (2017). Implementation of Lean Six Sigma framework with environmental considerations in an Indian automotive component manufacturing firm: a case study. Production Planning \& Control, 28(15), 1193-1211.

Bryman, A. (1989). Research methods and organization studies. Unwin Hyman, London, Boston.

Chakrabarty, A., \& Tan, K.C. (2007). The current state of six sigma application in services. Managing Service Quality: An International Journal, 17(2), 194-208. 
Chakraborty, A., \& Tan, K.C. (2012). Case study analysis of Six Sigma implementation in service organisations. Business Process Management Journal, 18(6), 992-1019.

Chen, M., \& Lyu, J. (2009). A Lean Six-Sigma approach to touch panel quality improvement. Production Planning and Control, 20(5), 445-454. https://doi.org/10.1080/09537280902946343

Chiarini, A. (2013). Differences between Six Sigma applications in manufacturing and the service industry. International Journal of Productivity and Quality Management, 12(3), 345-360.

Cohan, P.S. (2019). Scaling your startup. Apress, Berkeley, CA, Springer Nature Switzerland AG.

Coughlan, P., \& Coghlan, D. (2002). Action research for operations management. International Journal of Operations \& Production Management, 22(2), 220-240.

Cudney, E.A. \& Agustiady, T.K. (2017). Design for six sigma: a practical approach through innovation. Taylor \& Francis Group, London.

Dey, P.K., Bhattacharya, A., Ho, W., \& Clegg, B. (2015). Strategic supplier performance evaluation: A casebased action research of a UK manufacturing organisation. International Journal of Production Economics, 166, 192-214.

Dieste, M., Panizzolo, R., \& Garza-Reyes, J.A. (2020). Evaluating the impact of lean practices on environmental performance: evidences from five manufacturing companies. Production Planning \& Control, 31(9), 739-756. https://doi.org/10.1080/09537287.2019.1681535

Dieste, M., Panizzolo, R., \& Garza-Reyes, J.A. (2021). A systematic literature review regarding the influence of lean manufacturing on firms' financial performance. Journal of Manufacturing Technology Management, 32(9), 101-121. https://doi.org/10.1108/JMTM-08-2020-0304

Feinleib, D. (2011). Why startups fail: and how yours can succeed. Apress, Springer Nature Switzerland AG.

Garza-Reyes, J.A., Al-Balushi, M., Antony, J., \& Kumar, V. (2016). A Lean Six Sigma framework for the reduction of ship loading commercial time in the iron ore pelletising industry. Production Planning \& Control, 27(13), 1092-1111. https://doi.org/10.1080/09537287.2016.1185188

Garza-Reyes, J.A., Tangkeow, S., Kumar, V., \& Nadeem, S.P. (2018). Lean manufacturing adoption in the transport and logistics sector of Thailand - An exploratory study. In Proceedings of the International Conference on Industrial Engineering and Operations Management (pp. 104-115). IEOM Society, Bandung, Indonesia.

Gijo, E.V., Antony, J., \& Sunder, M.V. (2019). Application of lean six sigma in IT support services-a case study. The TQM Journal, 31(3), 417-435.

Gijo, E.V, Antony, J., Kumar, M., McAdam, R., \& Hernandez, J. (2014). An application of Six Sigma methodology for improving the first pass yield of a grinding process. Journal of Manufacturing Technology Management, 25(1), 125-135.

Gijo, E.V., \& Scaria, J. (2014). Process improvement through Six Sigma with Beta correction: a case study of manufacturing company. The International Journal of Advanced Manufacturing Technology, 71(14), 717-730.

Gilbert, I., \& Davies, S. (2011). A sales execution strategy guide for technology startups. Technology Innovation Management Review, 1(1), 32-36.

Gutierrez, D.M., Scavarda, L.F., Fiorencio, L., \& Martins, R.A. (2015). Evolution of the performance measurement system in the logistics department of a broadcasting company: an action research. International Journal of Production Economics, 160, 1-12.

Hase, S., \& Busch, C. (2018). The quintessence of sales. Springer, Cham, Springer Nature Switzerland AG. 
Hathaway, I. (2013). Tech starts: high-technology business formation and job creation in the United States. Ewing Marion Kauffman Foundation, Kansas City, United States

Jirasukprasert, P., Garza-Reyes, J.A., Kumar, V., \& K. Lim, M. (2014). A Six Sigma and DMAIC application for the reduction of defects in a rubber gloves manufacturing process. International Journal of Lean Six Sigma, 5(1), 2-21.

Karout, R., \& Awasthi, A. (2017). Improving software quality using Six Sigma DMAIC-based approach: a case study. Business Process Management Journal, 23(4), 842-856.

Krueger, D.C., Mellat Parast, M., \& Adams, S. (2014). Six Sigma implementation: a qualitative case study using grounded theory. Production Planning \& Control, 25(10), 873-889.

Kumar, N., Brint, A., Shi, E., Upadhyay, A., \& Ruan, X. (2019). Integrating sustainable supply chain practices with operational performance: an exploratory study of Chinese SMEs. Production Planning \& Control, 30(5-6), 464-478.

Kumar, S., \& Sosnoski, M. (2009). Using DMAIC Six Sigma to systematically improve shopfloor production quality and costs. International Journal of Productivity and Performance Management, 58(3), 254-273.

Kuvvetli, Ü., \& Firuzan, A.R. (2019). Applying Six Sigma in urban public transportation to reduce traffic accidents involving municipality buses. Total Quality Management \& Business Excellence, 30(1-2), 82107.

Kuwaiti, A.Al., \& Subbarayalu, A.V. (2017). Reducing patients' falls rate in an academic medical center (AMC) using six sigma "DMAIC" approach. International Journal of Health Care Quality Assurance, 30(4), 373-384.

Lameijer, B.A., Pereira, W., \& Antony, J. (2021). The implementation of lean six sigma for operational excellence in digital emerging technology companies. Journal of Manufacturing Technology Management, 32(9), 260-284.

Lee, H.H. (2014). The service marketing analysis by using six sigma management approach. Journal of Quality, 21(3), 133-148.

Li, N., Laux, C.M., \& Antony, J. (2019). How to use lean Six Sigma methodology to improve service process in higher education: A case study. International Journal of Lean Six Sigma, 10(4), 883-908.

Madhani, P.M. (2017). Six Sigma deployment in sales and marketing: enhancing competitive advantages. The IUP Journal of Business Strategy, 14(2), 40-63.

Mehrjerdi, Y.Z. (2013). A framework for six-sigma driven RFID-enabled supply chain systems. International Journal of Quality \& Reliability Management, 30(2), 142-160.

Mishra, N., \& Rane, S.B. (2019). Prediction and improvement of iron casting quality through analytics and Six Sigma approach. International Journal of Lean Six Sigma, 10(1), 189-210. https://doi.org/10.1108/IJLSS-11-2017-0122

Montgomery, D.C. (2007). Introduction to statistical quality control. John Wiley \& Sons, USA.

Muralidharan, K. (2015). Six Sigma for organizational excellence: A statistical approach. Springer, New Delhi, India.

Muralidharan, K., \& Raval, N. (2020). Six Sigma marketing: an innovative approach to achieve strategic goals of sustainable supply chain. In: Ramanathan, U., Ramanathan, R. (eds) Sustainable Supply Chains: Strategies, Issues, and Models. Springer, Cham, pp. 159-184.

Nadeem, S.P., Garza-Reyes, J.A., Anosike, A.I., \& Kumar, V. (2019). Coalescing the lean and circular economy. In 2019 Proceedings of the International Conference on Industrial Engineering and Operations Management (pp. 1082-1093). IEOM Society Bangkok, Thailand. http://www.ieomsociety.org/ieom2019/papers/279.pdf 
Noori, B., \& Latifi, M. (2018). Development of six sigma methodology to improve grinding processes. International Journal of Lean Six Sigma, 9(1), 50-63.

Oliya, E., Owlia, M.S., Shahrokh, Z.D., \& Olfat, L. (2012). Improving marketing process using six sigma techniques (case of Saman Bank). International Journal of Lean Six Sigma, 3(1), 59-73.

Patel, S. (2017). The tactical guide to six sigma implementation. Productivity Press, Boca Raton.

Pestorius, M.S. (2007). Apply six sigma to sales and marketing. Quality Control and Applied Statistics, 52(6), 629.

Prashar, A. (2020). Adopting six sigma DMAIC for environmental considerations in process industry environment. The TQM Journal, 32(6), 1241-1261.

Pyzdek, T., \& Keller, P. (2014). The six sigma handbook. McGraw-Hill Education, New York.

Salzarulo, P.A., Krehbiel, T.C., Mahar, S., \& Emerson, L.S. (2012). Six Sigma sales and marketing: application to NCAA basketball. American Journal of Business, 27(2), 113-132.

Sangabriel-Guillen, O., Temblador-Pérez, M.D.C., \& Rosa-Hernández, R.M.D.L. (2017). Use of value driver maps for six sigma project selection: a case study on sales and marketing for soft drinks bottling industry. Ingeniería, Investigación y Tecnología, 18(1), 55-65.

Saunders, M., Lewis, P., \& Thornhill, A. (2016). Research methods for business students (7th ed). Pearson, United Kingdom.

Shadish, W.R., Cook, T.D., \& Campbell, D.T. (2002). Experimental and quasi-experimental designs for generalized causal inference. Houghton Mifflin Company, Boston, New York.

Shamsuzzaman, M., Alzeraif, M., Alsyouf, I., \& Khoo, M.B.C. (2018). Using lean six sigma to improve mobile order fulfilment process in a telecom service sector. Production Planning \& Control, 29(4), 301314.

Sin, A.B., Zailani, S., Iranmanesh, M., \& Ramayah, T. (2015). Structural equation modelling on knowledge creation in six sigma DMAIC project and its impact on organizational performance. International Journal of Production Economics, 168, 105-117.

Skala, A. (2019). Digital startups in transition economies: challenges for management, entrepreneurship and education. Palgrave Pivot, Springer.

Srinivasan, K., Muthu, S., Devadasan, S.R., \& Sugumaran, C. (2016). Enhancement of sigma level in the manufacturing of furnace nozzle through DMAIC approach of six sigma: a case study. Production Planning \& Control, 27(10), 810-822.

Sunder, M.V., Mahalingam, S., \& Krishna, M.S.N. (2020). Improving patients' satisfaction in a mobile hospital using lean six sigma-a design-thinking intervention. Production Planning \& Control, 31(6), $512-526$

Swarnakar, V., \& Vinodh, S. (2016). Deploying lean six sigma framework in an automotive component manufacturing organization. International Journal of Lean Six Sigma, 7(3), 267-293. https://doi.org/10.1108/IJLSS-06-2015-0023

Swink, M., \& Jacobs, B.W. (2012). Six Sigma adoption: Operating performance impacts and contextual drivers of success. Journal of Operations Management, 30(6), 437-453.

Upadhyay, A., Akter, S., Adams, L., Kumar, V., \& Varma, N. (2019). Investigating “circular business models" in the manufacturing and service sectors. Journal of Manufacturing Technology Management, $30(3), 590-606$.

Upadhyay, A., Kumar, A., \& Akter, S. (2021). An analysis of UK retailers' initiatives towards circular economy transition and policy-driven directions. Clean Technologies and Environmental Policy, 1-9. 
Wartati et al.: A Six-Sigma DMAIC Approach to Improve the Sales Process of a ...

Yadav, N., Shankar, R., \& Singh, S.P. (2020). Impact of Industry4.0/ICTs, lean six sigma and quality management systems on organisational performance. The TQM Journal, 32(4), 815-835. https://doi.org/10.1108/TQM-10-2019-0251

Zhang, M., Wang, W., Goh, T.N., \& He, Z. (2015). Comprehensive six sigma application: a case study. Production Planning \& Control, 26(3), 219-234.

Appendix A. Waiting time in the onboarding stage

\begin{tabular}{|c|c|c|c|c|c|c|c|}
\hline \multirow{2}{*}{ No } & \multirow{2}{*}{$\begin{array}{c}\text { Date } \\
(\mathrm{dd} / \mathrm{mm} / \mathrm{yy})\end{array}$} & \multicolumn{2}{|c|}{ Registering merchant } & \multicolumn{2}{|c|}{ Generating contract } & \multirow{2}{*}{ Total time (minutes) } & \multirow{2}{*}{ Note } \\
\hline & & Time start & Time end & Time start & Time end & & \\
\hline 1 & $10 / 06 / 2019$ & $08: 48$ & $08: 56$ & $08: 56$ & 09:14 & 26 & - \\
\hline 2 & $10 / 06 / 2019$ & $09: 15$ & 09:19 & 09:19 & $09: 37$ & 22 & - \\
\hline 3 & $10 / 06 / 2019$ & $09: 38$ & $09: 42$ & $09: 42$ & $10: 00$ & 22 & - \\
\hline 4 & $10 / 06 / 2019$ & $10: 18$ & $10: 22$ & $10: 22$ & $10: 37$ & 19 & - \\
\hline 5 & $10 / 06 / 2019$ & $10: 38$ & $10: 42$ & $10: 42$ & $10: 57$ & 19 & - \\
\hline 6 & $10 / 06 / 2019$ & $11: 03$ & 11:08 & $11: 08$ & $11: 26$ & 23 & - \\
\hline 7 & $10 / 06 / 2019$ & $11: 27$ & $11: 33$ & $11: 33$ & $11: 51$ & 24 & - \\
\hline 8 & $10 / 06 / 2019$ & 13:04 & $13: 12$ & $13: 12$ & $13: 30$ & 26 & - \\
\hline 9 & $10 / 06 / 2019$ & $13: 31$ & $13: 40$ & $13: 40$ & $13: 58$ & 27 & - \\
\hline 10 & $10 / 06 / 2019$ & 14:01 & $14: 18$ & $14: 18$ & $14: 36$ & 35 & - \\
\hline 11 & $10 / 06 / 2019$ & $14: 49$ & $15: 09$ & $15: 09$ & $15: 27$ & 38 & - \\
\hline 12 & $10 / 06 / 2019$ & $15: 30$ & $15: 36$ & $15: 36$ & $15: 54$ & 24 & - \\
\hline 13 & $11 / 06 / 2019$ & $08: 40$ & $08: 46$ & $08: 46$ & 09:03 & 23 & - \\
\hline 14 & $11 / 06 / 2019$ & 09:22 & $09: 28$ & $09: 28$ & $09: 45$ & 23 & - \\
\hline 15 & $11 / 06 / 2019$ & $09: 48$ & $09: 52$ & $09: 52$ & $10: 09$ & 21 & - \\
\hline 16 & $11 / 06 / 2019$ & $10: 16$ & $10: 23$ & $10: 23$ & $10: 40$ & 24 & - \\
\hline 17 & $11 / 06 / 2019$ & $10: 50$ & $11: 02$ & $11: 02$ & $11: 19$ & 29 & - \\
\hline 18 & $11 / 06 / 2019$ & $11: 23$ & $11: 30$ & $11: 30$ & $11: 47$ & 24 & - \\
\hline 19 & $11 / 06 / 2019$ & $13: 14$ & $13: 19$ & $13: 19$ & $13: 36$ & 22 & - \\
\hline 20 & $11 / 06 / 2019$ & $13: 44$ & $13: 51$ & $13: 51$ & $14: 08$ & 24 & - \\
\hline 21 & $11 / 06 / 2019$ & $14: 35$ & $14: 44$ & $14: 44$ & $15: 01$ & 26 & - \\
\hline 22 & $11 / 06 / 2019$ & $15: 04$ & $15: 11$ & $15: 11$ & $15: 28$ & 24 & - \\
\hline 23 & $11 / 06 / 2019$ & $15: 29$ & $15: 35$ & $15: 35$ & $15: 52$ & 23 & - \\
\hline 24 & $12 / 06 / 2019$ & $08: 40$ & $08: 47$ & $08: 47$ & 09:03 & 23 & - \\
\hline 25 & $12 / 06 / 2019$ & 09:05 & $09: 12$ & $09: 12$ & $09: 27$ & 22 & - \\
\hline 26 & $12 / 06 / 2019$ & 09:29 & 09:34 & 09:34 & 09:50 & 21 & - \\
\hline 27 & $12 / 06 / 2019$ & $09: 51$ & $09: 56$ & $09: 56$ & $10: 11$ & 20 & - \\
\hline 28 & $12 / 06 / 2019$ & $10: 12$ & $10: 19$ & $10: 19$ & $10: 35$ & 23 & - \\
\hline 29 & $12 / 06 / 2019$ & $10: 36$ & $10: 43$ & $10: 43$ & $10: 58$ & 22 & - \\
\hline 30 & $12 / 06 / 2019$ & 11:06 & $11: 12$ & $11: 12$ & $11: 28$ & 22 & - \\
\hline 31 & $12 / 06 / 2019$ & $11: 29$ & $11: 35$ & $11: 35$ & $11: 50$ & 21 & - \\
\hline 32 & $12 / 06 / 2019$ & $13: 13$ & $13: 21$ & $13: 21$ & $13: 37$ & 24 & - \\
\hline 33 & $12 / 06 / 2019$ & $13: 38$ & $13: 46$ & $13: 46$ & 14:01 & 23 & - \\
\hline 34 & $12 / 06 / 2019$ & $14: 09$ & $14: 18$ & $14: 18$ & $14: 34$ & 25 & - \\
\hline 35 & $12 / 06 / 2019$ & $14: 44$ & $14: 49$ & $14: 49$ & 15:04 & 20 & - \\
\hline 36 & $12 / 06 / 2019$ & 15:06 & $15: 11$ & 15:11 & $15: 27$ & 21 & - \\
\hline 37 & $12 / 06 / 2019$ & $15: 29$ & $15: 37$ & $15: 37$ & $15: 52$ & 23 & - \\
\hline 38 & $12 / 06 / 2019$ & $15: 53$ & $15: 59$ & $15: 59$ & $16: 15$ & 22 & - \\
\hline 39 & $13 / 06 / 2019$ & 08:45 & 08:51 & 08:51 & 09:09 & 24 & - \\
\hline 40 & $13 / 06 / 2019$ & 09:10 & 09:14 & 09:14 & 09:32 & 22 & - \\
\hline 41 & $13 / 06 / 2019$ & 09:37 & 09:44 & 09:44 & 10:02 & 25 & - \\
\hline 42 & $13 / 06 / 2019$ & 10:07 & $10: 12$ & $10: 12$ & $10: 30$ & 23 & - \\
\hline 43 & $13 / 06 / 2019$ & 10:31 & $10: 34$ & $10: 34$ & $10: 52$ & 21 & - \\
\hline 44 & $13 / 06 / 2019$ & $11: 23$ & $11: 31$ & $11: 31$ & $11: 49$ & 26 & - \\
\hline
\end{tabular}


Wartati et al.: A Six-Sigma DMAIC Approach to Improve the Sales Process of a ...

\begin{tabular}{|c|c|c|c|c|c|c|c|}
\hline \multirow{2}{*}{ No } & \multirow{2}{*}{$\begin{array}{c}\text { Date } \\
(\mathrm{dd} / \mathrm{mm} / \mathrm{yy})\end{array}$} & \multicolumn{2}{|c|}{ Registering merchant } & \multicolumn{2}{|c|}{ Generating contract } & \multirow{2}{*}{ Total time (minutes) } & \multirow{2}{*}{ Note } \\
\hline & & Time start & Time end & Time start & Time end & & \\
\hline 45 & $13 / 06 / 2019$ & $12: 55$ & 13:02 & 13:02 & $13: 20$ & 25 & - \\
\hline 46 & $13 / 06 / 2019$ & $13: 28$ & $13: 37$ & $13: 37$ & $13: 55$ & 27 & - \\
\hline 47 & $13 / 06 / 2019$ & $13: 56$ & $14: 01$ & $14: 01$ & $14: 19$ & 23 & - \\
\hline 48 & $13 / 06 / 2019$ & $14: 33$ & $14: 39$ & $14: 39$ & $14: 57$ & 24 & - \\
\hline 49 & $14 / 06 / 2019$ & $09: 12$ & $09: 16$ & $09: 16$ & $09: 28$ & 16 & - \\
\hline 50 & $14 / 06 / 2019$ & $09: 29$ & $09: 33$ & $09: 33$ & $09: 45$ & 16 & - \\
\hline 51 & $14 / 06 / 2019$ & 09:47 & $09: 52$ & $09: 52$ & 10:04 & 17 & - \\
\hline 52 & $14 / 06 / 2019$ & $10: 05$ & $10: 09$ & $10: 09$ & $10: 21$ & 16 & - \\
\hline 53 & $14 / 06 / 2019$ & $10: 27$ & $10: 35$ & $10: 35$ & $10: 47$ & 20 & - \\
\hline 54 & $14 / 06 / 2019$ & $10: 48$ & $10: 58$ & $10: 58$ & $11: 10$ & 22 & - \\
\hline 55 & $14 / 06 / 2019$ & $11: 13$ & $11: 19$ & $11: 19$ & $11: 31$ & 18 & - \\
\hline 56 & $14 / 06 / 2019$ & $11: 32$ & $11: 39$ & $11: 39$ & $11: 51$ & 19 & - \\
\hline 57 & $14 / 06 / 2019$ & $11: 52$ & $11: 56$ & $11: 56$ & 12:08 & 16 & - \\
\hline 58 & $14 / 06 / 2019$ & 13:09 & $13: 16$ & $13: 16$ & $13: 28$ & 19 & - \\
\hline 59 & $14 / 06 / 2019$ & $13: 30$ & $13: 39$ & $13: 39$ & $13: 51$ & 21 & - \\
\hline 60 & $14 / 06 / 2019$ & $14: 31$ & $14: 37$ & $14: 37$ & $14: 49$ & 18 & - \\
\hline 61 & $14 / 06 / 2019$ & $15: 00$ & $15: 05$ & $15: 05$ & $15: 17$ & 17 & - \\
\hline 62 & $14 / 06 / 2019$ & $15: 18$ & $15: 22$ & $15: 22$ & $15: 34$ & 16 & - \\
\hline 63 & $14 / 06 / 2019$ & $15: 35$ & $15: 39$ & $15: 39$ & $15: 51$ & 16 & - \\
\hline 64 & $17 / 06 / 2019$ & 09:08 & $09: 15$ & $09: 15$ & $09: 33$ & 25 & - \\
\hline 65 & $17 / 06 / 2019$ & $09: 34$ & $09: 41$ & $09: 41$ & $10: 00$ & 26 & - \\
\hline 66 & $17 / 06 / 2019$ & 10:01 & 10:07 & 10:07 & $10: 25$ & 24 & - \\
\hline 67 & $17 / 06 / 2019$ & $10: 26$ & $10: 31$ & $10: 31$ & $10: 50$ & 24 & - \\
\hline 68 & $17 / 06 / 2019$ & $10: 51$ & $10: 56$ & $10: 56$ & $11: 14$ & 23 & - \\
\hline 69 & $17 / 06 / 2019$ & $11: 16$ & $11: 21$ & $11: 21$ & $11: 40$ & 24 & - \\
\hline 70 & $17 / 06 / 2019$ & $11: 41$ & $11: 45$ & $11: 45$ & $12: 03$ & 22 & - \\
\hline 71 & $17 / 06 / 2019$ & 13:08 & $13: 13$ & $13: 13$ & $13: 32$ & 24 & - \\
\hline 72 & $17 / 06 / 2019$ & $13: 38$ & $13: 46$ & $13: 46$ & $14: 04$ & 26 & - \\
\hline 73 & $17 / 06 / 2019$ & $14: 05$ & $14: 11$ & $14: 11$ & $14: 30$ & 25 & - \\
\hline 74 & $17 / 06 / 2019$ & $14: 31$ & $14: 38$ & $14: 38$ & $14: 56$ & 25 & - \\
\hline 75 & $17 / 06 / 2019$ & $15: 00$ & 15:09 & $15: 09$ & $15: 28$ & 28 & - \\
\hline 76 & $17 / 06 / 2019$ & $15: 29$ & $15: 33$ & $15: 33$ & $15: 51$ & 22 & - \\
\hline 77 & $18 / 06 / 2019$ & $09: 16$ & $09: 20$ & $09: 20$ & $09: 31$ & 15 & - \\
\hline 78 & $18 / 06 / 2019$ & $09: 32$ & $09: 36$ & $09: 36$ & $09: 46$ & 14 & - \\
\hline 79 & $18 / 06 / 2019$ & 09:47 & $09: 53$ & $09: 53$ & $10: 04$ & 17 & - \\
\hline 80 & $18 / 06 / 2019$ & $10: 14$ & $10: 18$ & $10: 18$ & $10: 28$ & 14 & - \\
\hline 81 & $18 / 06 / 2019$ & $10: 31$ & $10: 36$ & $10: 36$ & $10: 47$ & 16 & - \\
\hline 82 & $18 / 06 / 2019$ & $10: 48$ & $10: 54$ & $10: 54$ & 11:04 & 16 & - \\
\hline 83 & $18 / 06 / 2019$ & $11: 05$ & 11:09 & 11:09 & $11: 24$ & 19 & - \\
\hline 84 & $18 / 06 / 2019$ & $11: 25$ & $11: 30$ & $11: 30$ & $11: 45$ & 20 & - \\
\hline 85 & $18 / 06 / 2019$ & $11: 46$ & $11: 51$ & $11: 51$ & $12: 06$ & 20 & - \\
\hline 86 & $18 / 06 / 2019$ & 13:07 & $13: 12$ & $13: 12$ & $13: 27$ & 20 & - \\
\hline 87 & $18 / 06 / 2019$ & $13: 28$ & $13: 32$ & $13: 32$ & $13: 47$ & 19 & - \\
\hline 88 & $18 / 06 / 2019$ & $13: 48$ & $13: 51$ & $13: 51$ & $14: 06$ & 18 & - \\
\hline 89 & $19 / 06 / 2019$ & $09: 11$ & $09: 15$ & $09: 15$ & $09: 33$ & 22 & - \\
\hline 90 & $19 / 06 / 2019$ & $09: 34$ & $09: 39$ & $09: 39$ & $09: 57$ & 23 & - \\
\hline 91 & $19 / 06 / 2019$ & $09: 59$ & $10: 06$ & $10: 06$ & $10: 24$ & 25 & - \\
\hline 92 & $19 / 06 / 2019$ & $10: 25$ & $10: 33$ & $10: 33$ & $10: 51$ & 26 & - \\
\hline 93 & $19 / 06 / 2019$ & $11: 01$ & $11: 09$ & $11: 09$ & $11: 27$ & 26 & - \\
\hline 94 & $19 / 06 / 2019$ & $11: 28$ & $11: 36$ & $11: 36$ & $11: 54$ & 26 & - \\
\hline 95 & $19 / 06 / 2019$ & $13: 01$ & $13: 08$ & $13: 08$ & $13: 26$ & 25 & - \\
\hline 96 & $19 / 06 / 2019$ & $13: 27$ & $13: 31$ & $13: 31$ & $13: 49$ & 22 & - \\
\hline 97 & $19 / 06 / 2019$ & $14: 40$ & $14: 46$ & $14: 46$ & $15: 04$ & 24 & - \\
\hline 98 & $19 / 06 / 2019$ & $15: 08$ & $15: 16$ & $15: 16$ & $15: 34$ & 26 & - \\
\hline 99 & $19 / 06 / 2019$ & $15: 35$ & $15: 40$ & $15: 40$ & $15: 58$ & 23 & - \\
\hline 100 & $19 / 06 / 2019$ & $15: 59$ & $16: 06$ & $16: 06$ & $16: 24$ & 25 & - \\
\hline 101 & $20 / 06 / 2019$ & $09: 25$ & $09: 31$ & $09: 31$ & $09: 58$ & 33 & - \\
\hline 102 & $20 / 06 / 2019$ & $09: 59$ & $10: 06$ & $10: 06$ & $10: 33$ & 34 & - \\
\hline 103 & $20 / 06 / 2019$ & $10: 35$ & $10: 43$ & $10: 43$ & $11: 10$ & 35 & - \\
\hline 104 & $20 / 06 / 2019$ & $11: 11$ & $11: 16$ & $11: 16$ & $11: 43$ & 32 & - \\
\hline 105 & $20 / 06 / 2019$ & $13: 02$ & $13: 09$ & 13:09 & $13: 36$ & 34 & - \\
\hline
\end{tabular}


Wartati et al.: A Six-Sigma DMAIC Approach to Improve the Sales Process of a ...

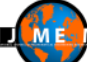

\begin{tabular}{|c|c|c|c|c|c|c|c|}
\hline \multirow{2}{*}{ No } & \multirow{2}{*}{$\begin{array}{c}\text { Date } \\
(\mathrm{dd} / \mathrm{mm} / \mathrm{yy})\end{array}$} & \multicolumn{2}{|c|}{ Registering merchant } & \multicolumn{2}{|c|}{ Generating contract } & \multirow{2}{*}{ Total time (minutes) } & \multirow{2}{*}{ Note } \\
\hline & & Time start & Time end & Time start & Time end & & \\
\hline 106 & $20 / 06 / 2019$ & $13: 37$ & $13: 44$ & $13: 44$ & $14: 11$ & 34 & - \\
\hline 107 & $20 / 06 / 2019$ & $14: 12$ & $14: 20$ & $14: 20$ & $14: 47$ & 35 & - \\
\hline 108 & $20 / 06 / 2019$ & $14: 48$ & $14: 58$ & $14: 58$ & $15: 25$ & 37 & - \\
\hline 109 & $20 / 06 / 2019$ & $15: 27$ & $15: 33$ & $15: 33$ & $16: 00$ & 33 & - \\
\hline 110 & $20 / 06 / 2019$ & $16: 01$ & $16: 05$ & $16: 05$ & $16: 32$ & 31 & - \\
\hline 111 & $20 / 06 / 2019$ & $16: 35$ & $16: 42$ & $16: 42$ & $17: 09$ & 34 & - \\
\hline 112 & $20 / 06 / 2019$ & $17: 10$ & $17: 18$ & $17: 18$ & $17: 45$ & 35 & - \\
\hline 113 & $20 / 06 / 2019$ & $17: 47$ & $17: 55$ & $17: 55$ & $18: 22$ & 35 & - \\
\hline 114 & $20 / 06 / 2019$ & $18: 23$ & $18: 29$ & $18: 29$ & $18: 56$ & 33 & - \\
\hline 115 & $20 / 06 / 2019$ & $18: 58$ & 19:07 & 19:07 & $19: 24$ & 36 & - \\
\hline 116 & $21 / 06 / 2019$ & $09: 30$ & $09: 34$ & $09: 34$ & $09: 50$ & 20 & - \\
\hline 117 & $21 / 06 / 2019$ & $09: 51$ & $09: 56$ & $09: 56$ & $10: 11$ & 20 & - \\
\hline 118 & $21 / 06 / 2019$ & $10: 15$ & $10: 21$ & $10: 21$ & $10: 37$ & 22 & - \\
\hline 119 & $21 / 06 / 2019$ & $10: 38$ & $10: 44$ & $10: 44$ & $11: 00$ & 22 & - \\
\hline 120 & $21 / 06 / 2019$ & $11: 02$ & $11: 09$ & $11: 09$ & $11: 25$ & 23 & - \\
\hline 121 & $21 / 06 / 2019$ & $11: 26$ & $11: 31$ & $11: 31$ & $11: 47$ & 21 & - \\
\hline 122 & $21 / 06 / 2019$ & $13: 10$ & $13: 17$ & $13: 17$ & $13: 33$ & 23 & - \\
\hline 123 & $21 / 06 / 2019$ & $13: 34$ & $13: 37$ & $13: 37$ & $13: 53$ & 19 & - \\
\hline 124 & $21 / 06 / 2019$ & $14: 03$ & $14: 11$ & $14: 11$ & $14: 27$ & 24 & - \\
\hline 125 & $21 / 06 / 2019$ & $14: 28$ & $14: 32$ & $14: 32$ & $14: 48$ & 20 & - \\
\hline 126 & $21 / 06 / 2019$ & $14: 49$ & $14: 55$ & $14: 55$ & $15: 13$ & 24 & - \\
\hline 127 & $21 / 06 / 2019$ & $15: 14$ & $15: 20$ & $15: 20$ & $15: 38$ & 24 & - \\
\hline 128 & $21 / 06 / 2019$ & $15: 42$ & $15: 46$ & $15: 46$ & $16: 04$ & 22 & - \\
\hline 129 & $21 / 06 / 2019$ & $16: 05$ & $16: 09$ & $16: 09$ & $16: 27$ & 22 & - \\
\hline 130 & $21 / 06 / 2019$ & $16: 29$ & $16: 42$ & $16: 42$ & $17: 00$ & 31 & - \\
\hline 131 & $24 / 06 / 2019$ & $09: 12$ & 09:17 & $09: 17$ & $09: 32$ & 20 & - \\
\hline 132 & $24 / 06 / 2019$ & $09: 33$ & $09: 37$ & $09: 37$ & $09: 52$ & 19 & - \\
\hline 133 & $24 / 06 / 2019$ & $09: 54$ & $09: 59$ & $09: 59$ & $10: 14$ & 20 & - \\
\hline 134 & $24 / 06 / 2019$ & $10: 15$ & $10: 22$ & $10: 22$ & $10: 37$ & 22 & - \\
\hline 135 & $24 / 06 / 2019$ & $10: 39$ & $10: 48$ & $10: 48$ & $11: 03$ & 24 & - \\
\hline 136 & $24 / 06 / 2019$ & 11:04 & $11: 13$ & $11: 13$ & $11: 28$ & 24 & - \\
\hline 137 & $24 / 06 / 2019$ & $11: 31$ & $11: 37$ & $11: 37$ & $11: 52$ & 21 & - \\
\hline 138 & $24 / 06 / 2019$ & $13: 01$ & $13: 08$ & $13: 08$ & $13: 23$ & 22 & - \\
\hline 139 & $24 / 06 / 2019$ & $13: 25$ & $13: 30$ & $13: 30$ & $13: 45$ & 20 & - \\
\hline 140 & $24 / 06 / 2019$ & $13: 46$ & $13: 50$ & $13: 50$ & $14: 05$ & 19 & - \\
\hline 141 & $24 / 06 / 2019$ & $14: 07$ & $14: 16$ & $14: 16$ & $14: 31$ & 24 & - \\
\hline 142 & $24 / 06 / 2019$ & $14: 32$ & $14: 41$ & $14: 41$ & $14: 56$ & 24 & - \\
\hline 143 & $24 / 06 / 2019$ & $15: 08$ & $15: 11$ & $15: 11$ & $15: 26$ & 18 & - \\
\hline 144 & $24 / 06 / 2019$ & $15: 33$ & $15: 35$ & $15: 35$ & $15: 50$ & 17 & - \\
\hline 145 & $24 / 06 / 2019$ & $15: 51$ & $15: 53$ & $15: 53$ & $16: 08$ & 17 & - \\
\hline
\end{tabular}

